\title{
A narrative review of the migration and invasion features of non-small cell lung cancer cells upon xenobiotic exposure: insights from in vitro studies
}

\author{
Catarina Albuquerque ${ }^{1 \#}$, Rita Manguinhas ${ }^{1 \#}$, João G. Costa ${ }^{2}$, Nuno Gil ${ }^{3}$, Jordi Codony-Servat ${ }^{4}$, \\ Matilde Castro ${ }^{1}$, Joana P. Miranda ${ }^{1}$, Ana S. Fernandes ${ }^{2}$, Rafael Rosell ${ }^{4,5,6}$, Nuno G. Oliveira ${ }^{1}$ \\ ${ }^{1}$ Research Institute for Medicines (iMed.ULisboa), Faculty of Pharmacy, Universidade de Lisboa, Lisboa, Portugal; ${ }^{2}$ CBIOS, Universidade Lusófona's \\ Research Center for Biosciences \& Health Technologies, Lisboa, Portugal; ${ }^{3}$ Lung Cancer Unit, Champalimaud Centre for the Unknown, Lisboa, \\ Portugal; ${ }^{4}$ Laboratory of Oncology/Pangaea Oncology S.L., Quirón-Dexeus University Institute, Barcelona, Spain; ${ }^{5}$ Laboratory of Cellular and \\ Molecular Biology, Institute for Health Science Research Germans Trias i Pujol (IGTP), Campus Can Ruti, Barcelona, Spain; ${ }^{6}$ Internal Medicine \\ Department, Universitat Autónoma de Barcelona, Campus de la UAB, Barcelona, Spain \\ Contributions: (I) Conception and design: C Albuquerque, R Manguinhas, NG Oliveira; (II) Administrative support: NG Oliveira; (III) Provision \\ of study materials or patients: None; (IV) Collection and assembly of data: C Albuquerque, R Manguinhas; (V) Data analysis and interpretation: C \\ Albuquerque, R Manguinhas; (VI) Manuscript writing: All authors; (VII) Final approval of manuscript: All authors. \\ \#These authors contributed equally to this work. \\ Correspondence to: Nuno G. Oliveira. Research Institute for Medicines (iMed.ULisboa), Faculty of Pharmacy, Universidade de Lisboa, Lisboa, \\ Portugal. Email: ngoliveira@ff.ulisboa.pt.
}

\begin{abstract}
Lung cancer (LC) is the leading cause of cancer deaths worldwide, being non-small lung cancer (NSCLC) sub-types the most prevalent. Since most LC cases are only detected during the last stage of the disease the high mortality rate is strongly associated with metastases. For this reason, the migratory and invasive capacity of these cancer cells as well as the mechanisms involved have long been studied to uncover novel strategies to prevent metastases and improve the patients' prognosis. This narrative review provides an overview of the main in vitro migration and invasion assays employed in NSCLC research. While several methods have been developed, experiments using conventional cell culture models prevailed, specifically the wound-healing and the transwell migration and invasion assays. Moreover, it is provided herewith a summary of the available information concerning chemical contaminants that may promote the migratory/ invasive properties of NSCLC cells in vitro, shedding some light on possible LC risk factors. Most of the reported agents with pro-migration/invasion effects derive from cigarette smoking [e.g., Benzo(a)pyrene and cadmium] and air pollution. This review further presents several studies in which different dietary/ plant-derived compounds demonstrated to impair migration/invasion processes in NSCLC cells in vitro. These chemicals that have been proposed as anti-migratory consisted mainly of natural bioactive substances, including polyphenols non-flavonoids, flavonoids, bibenzyls, terpenes, alkaloids, and steroids. Some of these compounds may eventually represent novel therapeutic strategies to be considered in the future to prevent metastasis formation in LC, which highlights the need for additional in vitro methodologies that more closely resemble the in vivo tumor microenvironment and cancer cell interactions. These studies along with adequate in vivo models should be further explored as proof of concept for the most promising compounds.
\end{abstract}

Keywords: Non-small cell lung cancer (NSCLC); migration; invasion; in vitro; xenobiotics

Submitted Feb 16, 2021. Accepted for publication May 10, 2021.

doi: $10.21037 /$ tlcr-21-121

View this article at: http://dx.doi.org/10.21037/tlcr-21-121 


\section{Introduction}

Amongst the various types of cancers worldwide, lung cancer (LC) is not only the most frequently diagnosed (considering men and women combined) (1) but also the leading cause of death in oncological patients $(1,2)$. It can be divided into two main types: small-cell lung cancer (SCLC) and non-small cell lung cancer (NSCLC), being the latter the most common. NSCLC includes adenocarcinoma, large-cell carcinoma, and squamous cell carcinoma (3). Since most LC cases are only detected during the last stage of the disease, i.e., stage IV, the high mortality rate is strongly associated with metastases, which can be commonly defined as the propagation of cancer from the primary site to different organs or tissues (4). This process has indeed a great impact on the success of treatment, which is not usually achievable with the different therapy modalities currently available. The formation of metastasis involves cell growth and migration through the extracellular matrix (ECM), penetration of vessels, resistance to anoikis while in circulation, extravasation at metastatic tissue, and formation of a new tumor $(3,5)$.

The knowledge on the cellular and molecular mechanisms underlying the formation of NSCLC metastases is a topic of utmost importance in clinical oncology that is continuously being updated and revised. Popper (6) highlighted the key importance of angiogenesis, hypoxia and stroma as well as the escape from immune cell system for tumor growth/establishment and lung cancer cell migration. In addition, the features associated with the vascular invasion (lymphatic and hematologic), extravasation and the creation of a distant metastatic focus were also extensively reviewed by this author (6). The wide range of organs that may be affected upon lung cancer metastization is a distinct feature that contrasts with many other types of cancer. The preferential sites for this critical event are usually the brain, bone, respiratory system, adrenal, and liver (7). While a similar pattern, and thus common mechanisms, can be ascribed for the colonization of lung cancer cells regardless of the organ affected, diverse influencing factors and mechanistic data have been described for each of the target organ metastases.

It should be mentioned that the description of the specific role of each player and the multiple signaling pathways involved in the highly complex metastatic process is beyond the scope of our current review article. Comprehensive reviews on the factors that influence the formation of NSCLC metastasis and several recognized mechanisms involved have been recently published $(7,8)$. To properly address this topic some aspects need to be considered, particularly the role of lung cancer stem cells and tumor microenvironment, bearing in mind that the latter not only includes the lung cancer cells but also the role of stromal cells (e.g., cancer-associated fibroblasts, immune cells, and vascular endothelial cells) and the extracellular matrix. Xie et al. (8) depicted some of the mechanisms associated with the tumor microenvironment and summarized several specific factors and their functions. These elements include growth factors (e.g., FGRF-1, EGFR and VEGF), adhesion molecules (e.g., CADM2, CADM4, E-cadherin, $\mathrm{N}$-cadherin and vimentin), chemokines (e.g., CXCL6) and inflammatory cytokines (particularly IL-1 $\beta$ and IL-6), lactic acid, oxygen, matrix metalloproteinases (e.g., MMP-2 and MMP-9) and a number of other additional elements.

Several genes that might regulate, either positively or negatively, NSCLC metastasis formation through a diversity of pathways have also been described and reviewed (8). In addition, numerous non-coding RNAs, including microRNAs (miRNA) have also been pointed to regulate the EMT, angiogenesis, among other pathways. Some of these miRNAs, including miR-148a-5p/miR-148a-3p (9), miR-135b (10), miR-520 (11) and miR-616-5p (12), have been shown to be modulated in vitro by xenobiotics. Moreover, miR-210 is an important element overexpressed in late stages of NSCLC (13) that can be released by exosomes, being important to mention that these extracellular vesicles are associated with many aspects of lung metastization, which are also relevant in a mechanistic perspective, through their direct and indirect roles (8).

Migration and invasion of cancer cells, such as LC cells, are processes intrinsically related to metastasis formation, and therefore extremely relevant as potential targets for new therapeutic alternatives (4). In general terms, migration corresponds to the movement of the cell on top or within a substrate while moving from one location to another. There are essentially two types of cell migration, i.e., single-cell and large cluster movement (or collective) (14). The first type can be subdivided in amoeboid, when there is no adhesion involved, and in mesenchymal migration when there is cell attachment to the extracellular matrix (5). Mesenchymal migration is associated with the epithelial to mesenchymal transition (EMT), considered a key mechanism that has been denoted as critical for cancer cell invasiveness (15). Collective cell migration consists of the progression of a large cluster of cells that do not undergo EMT and maintain cell-cell junction integrity. The traction is caused by a re-organization of the actin cytoskeleton and 
there is an organization of the tasks of mobile and nonmobile cells in the cluster $(16,17)$. The invasion processes are also crucial in carcinogenesis. Invasion refers to cell migration, that occurs through a $3 \mathrm{D}$ matrix in a destructive manner. It involves not only the ability of cells to migrate but also to adhere and to modify the surrounding tissues (17). In malignant tumors, this type of cell movement occurs during the infiltration of metastatic tissues $(5,14)$.

The effect of several compounds on the migration/ invasion of LC cells in vitro has been the main focus of many experimental studies performed in the last decade. Some reports aim at better understanding which exogenous factors could significantly promote the progression of cancer cells towards a more aggressive phenotype. In fact, these studies often explore the aforementioned underlying mechanisms associated with these changes, being important to further identify chemicals that may constitute risk factors for LC. Additionally, various bioactive substances of natural origin have shown inhibitory properties on the migration and/or invasion of NSCLC cells. In this sense, some of these chemicals have been investigated as putative therapeutic agents against LC. They are usually natural compounds that are likely to display better safety profiles in healthy normal cells as compared with the drugs classically used in standard LC chemotherapy.

In the present review, the most common migration/ invasion in vitro assays are firstly described. This introductory section intends to highlight the main characteristics of a given migration/invasion endpoint (Table S1). This may be relevant to better understand the main findings obtained in the studies performed with the migration/invasion modulators. In addition, an overview of the in vitro studies regarding the effect of xenobiotics, in particular chemical contaminants as well as dietary/plantderived compounds, on NSCLC cell migration and invasion is then provided. This work was performed with the aim of elucidating which compounds have been proposed as promoters (Table S2) or inhibitors (Table S3) of the in vitro migration and/or invasion of NSCLC cells, expecting that this may shed some light on putative LC risk factors or alternative bioactive drugs, respectively.

We present the following article in accordance with the Narrative Review reporting checklist (available at http:// dx.doi.org/10.21037/tlcr-21-121).

\section{Methods}

In vitro studies were selected after an extensive search via PubMed, accessed between May and November of 2020. A publication date interval was defined as from 1999 to 2020 and only articles written in English were included. The main keywords used for the identification of the research articles were a combination of "non-small cell lung cancer"/“NSCLC", "migration", "invasion", "in vitro", "inhibition", "promotion", "extract", "xenobiotic" and "compound". All in vitro studies identified that did not include migration and/or invasion experiments with NSCLC cell lines were excluded. Additional recent articles, including review articles addressing mechanisms of NSCLC metastization were also included in this work.

\section{In vitro experimental approaches to assess migration and invasion features}

As above mentioned, when referring to in vitro assays, the term "migration" defines the movement of cells on a 2D surface and the term "invasion" describes the movement of cells on a 3D extracellular matrix. In this section, a summary of the most frequently used migration and invasion methods for NSCLC research is shown in Table S1. Nevertheless, other methods and different experimental procedures can also be used within this field. Moreover, for some of the assays herein mentioned, the experimental procedures are not detailed since this description is beyond the scope of the review.

\section{Migration assays}

For the evaluation of the migratory behavior of NSCLC cells in vitro, the two main assays frequently used are: (I) transwell migration assay and (II) wound-healing assay. Other assays (III), although less frequently applied, include the fence assay (18), time-lapse cell tracking $(19,20)$, cell exclusion zone assay $(19,21,22)$, and spheroid migration assay (23).

(I) Transwell migration assay (Boyden chamber). This method is used for single-cell migration studies and consists of two chambers separated by plastic inserts with a membrane that can have various pore sizes depending on the cell type of interest. For this reason, it can be adapted to various types of cell lines and has been extensively used in NSCLC cells $(11,24-40)$, where it has proven to be very useful. In the transwell assay, cells migrate vertically through the membrane from the upper chamber to the lower. The movement is promoted by using a chemoattractant, such as fetal bovine 
serum (FBS) or N-Formyl-Met-Leu-Phe (FMLP), in the lower chamber medium $(5,41)$. There are two main methods for the quantification of the cells that migrated through the membrane. Both methods start with the removal of non-migrated cells and the fixation of the cells that migrated (e.g., paraformaldehyde, methanol or $70 \%$ ethanol). The first uses cytological staining (e.g., crystal violet, hematoxylin, or Giemsa), after which the cells are counted, or the dye is eluted and quantified by absorbance. In the second method, as an alternative, cells can be stained with fluorescent dyes, namely Hoechst $33342(27,29,39)$ and DAPI (36). This assay is simple to execute and there is no need for specific equipment besides the culture inserts. However, one difficulty relies on the need for optimization of the duration of analysis according to each cell type (5). There is also a need for ascertaining non-toxic concentrations of the desirable compounds to be tested since toxic concentrations would interfere with cell viability and hide possible effects in cell migration and invasion processes.

(II) Wound-healing (scratch) assay. This assay consists of the infliction of a wound or a scratch in culture plates where cells were grown to form a confluent monolayer. The wound is commonly achieved using a micropipette tip and the cells are allowed to migrate into the wound space (42). Cell migration can be determined according to the decrease in the wound area or in the distance between the wound edges since the cells will migrate towards the closure of this gap space. The subsequent analysis is usually performed by monitoring the distance in wound closure under a microscope during a defined time period or by time-lapse imaging and compared to an initial control (time $0 \mathrm{~h})(5,42-44)$. The major advantages of this method include the low price, simplicity of setup and analysis, and applicability in different cell types. One major disadvantage is the possibility of mechanical cell damage as well as the inability to completely control wound size since it is performed manually. Another issue is the presence of possible interfering factors, such as cytotoxicity, variation of cell-cell adhesions, and cell crowding, that can affect the results obtained (42).

(III) Other migration assays. In what concerns other methodologies, the fence and cell exclusion zone assays are essentially the opposite of each other. They are similar to the wound-healing assay with the advantage of reproducing same size cell-free zones and no risk of causing cell damage. In the fence assay, a fence is placed on a culture dish and cells are seeded inside it. The fence is then removed and the migration of cells out of the initial area is analyzed. In contrast, in the cell exclusion zone assay, the cells are seeded outside of the fence, and the migration inward into the cell-free zone is analyzed (5).

Time-lapse cell tracking consists of using timelapse microscopy together with a specific computer software to follow the migratory trajectory of single cells in a certain time period. For example, Huang et al. (19) combined the cell exclusion zone assay with time-lapse tracking for $20 \mathrm{~h}$ after the removal of the fence. Using this technique, besides measuring the migration area, the authors also obtained information regarding the trajectories and velocity.

In the spheroid migration assay, multicellular spheroids are placed in chamber slides or other plastic surfaces and cells start migrating to the area surrounding each spheroid. This area is then quantified by microscopy. Rao et al. (23) used this method to evaluate the effect of an adenovirus expressing an antisense transcript for the gene expressing the matrix metalloproteinase-9 (MMP9) and the gene of urokinase-type plasminogen activator receptor (uPAR) on the migration of the NSCLC cell line A549.

\section{Invasion assays}

Regarding the evaluation of invasion properties of NSCLC cells in vitro, the standard method is the transwell invasion assay. The major difference between this assay and the transwell migration assay is the incorporation of an ECMmimic coating on the membrane of the inserts. This coating only allows the passage of invasive cells that, in contrast with the non-invasive counterparts, can degrade ECM. In NSCLC cell studies the most used matrix is Matrigel $(25,36,40)$.

Another assay which has been frequently used is the gelatin zymography assay $(26,28,45,46)$. This method evaluates the activity of matrix metalloproteinases with gelatinase activity, that have an essential role in the migration and invasiveness of tumor cells. Usually, their 
activity can be measured by electrophoresis in a sodium dodecyl sulfate (SDS)-polyacrylamide gel with gelatin.

The spheroid gel invasion assay $(21,47)$ and $3 \mathrm{D}$ cell tracking (47) have also been reported. In the former, cell spheroids are transferred to a $3 \mathrm{D}$ matrix, such as collagen I gel or fibrin, and invasive cells will separate from this cluster and degrade the matrix, closely mimicking invasion in vivo. The second assay is similar to the time-lapse migration assay, it also uses time-lapse microscopy together with a specific computer software (5), such as Image-Pro (Media Cybernetics Inc., Silver Spring, MD), and is able to track single-cell invasion (47).

Lastly, other complementary methodologies have been used to characterize invasiveness, such as the cell matrixadhesion assay $(26,28,46,48)$. This assay consists of the quantification of cells adherent to a specific substrate, usually type I collagen. Most commonly, cells are incubated in multi-well plates coated with the substrate in conditions adapted to each cell type. Subsequently, nonadherent cells are removed and the adherent cells are stained with Crystal Violet, being the absorbance then measured. The results are expressed as percent of adhesion.

\section{Exposure to lung carcinogens and other toxic xenobiotics increases the migration and invasion potential of NSCLC cells}

There have been extensive data published concerning the potential contribution of exposure to certain contaminants and known carcinogens in the development and progression of LC. Particularly, in NSCLC, the xenobiotics that may promote the migration and invasion of cancer cells can be organized into two main groups: (I) tobacco smoke carcinogens and (II) air pollution contaminants. In addition to these two groups, other chemical agents reported to increase the migration/ invasion properties of NSCLC should also be considered, being allocated in a third group (III). However, it should be of note that some carcinogens herein described can indeed belong to more than one category, since it is well known that we can be exposed to them by different ways, e.g., benzo(a)pyrene $[\mathrm{B}(\mathrm{a}) \mathrm{P}]$ or cadmium (Cd). An overview of some relevant in vitro studies available focusing on this subject is provided in Table S2. In this table, we present information on the key findings reported by the authors in their original studies mainly using the migration and invasion assays. Nonetheless, some of these findings were achieved using other methodologies. It is also important to mention that additional major conclusions from these studies have been emphasized by the authors, albeit not mentioned in Table S2.

\section{Tobacco smoke contaminants}

Tobacco smoke is the most recognized risk factor for LC $(35,49)$ and, regarding migration and invasion of NSCLC, four particular carcinogens have been highlighted: nicotine, nitrosamine 4-(methylnitrosamino)-1-(3-pyridyl)-1butanone (NNK), B(a)P, and Cd. It has been proposed that nicotine, an alkaloid of tobacco plants, promotes invasion and migration of NSCLC cells via the $\alpha 7$ nicotinic acetylcholine receptors ( $\alpha 7-\mathrm{nAChRs})(50)$ and through the induction of Stathmin-3 (STMN3) and G1 to S phase transition 1 (GSPT1) genes (51). More recently, it was shown that this alkaloid could also affect proliferation, migration, and invasion of NSCLC cells through overexpression of long intergenic non-protein coding RNA 460 (LINC00460), which, in turn, induces the activation of the phosphatidylinositol 3-kinase/protein kinase B (PI3K/ Akt) signaling pathway (52).

Two different studies have investigated the mechanism through which NNK could promote migratory and invasive features in NSCLC cell lines. Firstly, it was verified by Shen et al. (53) that NNK acted through the activation of the $\alpha 7 \mathrm{nAChR}$, which in turn plays an important role in the activation of the $\mathrm{c}-\mathrm{Src} / \mathrm{PKC} / \mathrm{FAK}$ loop. Protein kinase $\mathrm{C}(\mathrm{PKC})$ is involved in cancer cell migration and phosphorylates focal adhesion kinases (FAK), which then regulate cell motility and tumor invasion by forming a complex with c-Src. This kinase phosphorylates PKC and FAK creating a signaling loop that is activated by NNK, promoting cell migration and metastasis (53). Recently, Wang et al. (54) observed that the exposure to NNK promoted migration and invasion of cancer cells through the increase in Twist protein levels, a transcription factor that had been previously associated with migration and invasion of different types of tumor cells. This transcription factor, in turn, increased N-cadherin mRNA expression, downregulated E-cadherin, a marker of epithelial cells, and therefore promoted EMT (54).

Regarding $\mathrm{B}(\mathrm{a}) \mathrm{P}$, the most carcinogenic and well-known member of the large polycyclic aromatic hydrocarbon (PAH) group, it was proposed that this compound augmented migration and invasion of NSCLC cells partially through the increase of Interleukin 8 (IL-8), a cytokine present in high levels in LC patients' serum. In addition, $\mathrm{B}(\mathrm{a}) \mathrm{P}$ also 
increased the secretion of two chemokines involved in the development and metastasis of different tumors, chemokine (C-C motif) ligand 2 (CCL2) and Chemokine (C-C motif) ligand 3 (CCL3) (55). Another study showed that $\mathrm{B}(\mathrm{a}) \mathrm{P}$ activates the tumor necrosis factor- $\alpha(\mathrm{TNF}-\alpha)$ pathway by increasing the expression of the protein levels of TNF- $\alpha$, nuclear factor kappa B (NF- $\mathrm{B}$ ), caspase-3 and caspase-8, and through this activation can promote LC metastasis (56).

Other studies have focused on the effects of cadmium exposure on migration/invasion of LC cells. Although this carcinogen is included in the groups of occupational, environmental, and food contaminants, the primary source for the majority of the population is tobacco smoke, followed closely by contaminated food and water (57). It was observed that, for the promotion of migration and invasion, Cd directly induced Notch 1 signaling and activated it indirectly through the HIF-1 $\alpha$ and Akt/ERK/ S6K1 pathways (58). Additionally, Cd upregulated the transcription factor associated with malignant behavior high-mobility group AT-hook (HMGA2) (37), upregulated phosphorylated extracellular signal-regulated kinase (p-ERK) (35), increased reactive oxygen species (ROS) levels and autophagy (38) as well as enhanced transforming growth interacting factor (TGIF) levels (57).

\section{Air pollution contaminants}

Regarding contaminants present in the air, particulate matters with less than $2.5 \mu \mathrm{m}$ of diameter (PM2.5), oxygenated-PAHs (Oxy-PAHs), gaseous nitric oxide (gNO), and bisphenol A (BPA) have been proposed as promoters of migration and invasion of NSCLC cells. PM2.5 seemed to increase intracellular ROS and the expression of loc146880, a long non-coding RNA (lncRNA) associated with LC metastasis, which promoted cell migration, invasion, and autophagy (59). Additionally, concomitant exposure of PM2.5 together with cigarette smoke caused an increase in the expression of other IncRNA, LCPAT1, that enhanced migration and invasion of LC cells (60). Other study showed a differential expression of various genes after exposure to PM2.5, many of them involved in cell motility, proliferation, and invasion. Two genes in particular, matrix metalloproteinase-1 (MMP-1) and interleukin-1 $\beta$ (IL-1 $\beta$ ), were the most up-regulated, and it was proposed that these played a critical role in cell migration and invasion (61).

On the other hand, Oxy-PAHs, in particular 9-fluorenone, promoted migration and invasion of LC cells by increasing the expression of vimentin and alpha-smooth muscle active ( $\alpha$-SMA), markers of mesenchymal cells, and downregulating E-cadherin (increasing EMT) (24). Regarding gaseous nitric oxide (gNO), despite the fact that it can also be present in cigarette smoke, its primary source is air pollution by fossil fuel combustion. This contaminant promoted cell migration and invasion of NSCLC cells via activation of the inducible isoform of L-arginine through nitric oxide synthase (iNOS) causing an increase in the expression of c-Jun [activator protein 1 (AP-1) subunit] and NF- $\kappa$ B. Alternatively, gNO could directly activate NF- $\kappa \mathrm{B}$, increasing MMP-2 levels and simultaneously downregulating the tissue inhibitor of MMP-2 (TIMP-2) (62).

Lastly, BPA is a xenoestrogen that can be associated with LC development via inhalation exposure. It was shown that cells exposed to BPA had upregulation of metalloproteinases MMP-2 and MMP-9 and upregulation of GPER/EGFR/ ERK1/2 signals (34). In a recent study, it was suggested that BPA promotes EMT by acting on the Snail-1/Cx43/ERR $\gamma$ signaling pathway. BPA increased the levels of estrogenrelated receptor $\gamma(\mathrm{ERR} \gamma)$ that in turn activated the known EMT markers Snail1/Cx43 signaling (63).

\section{Other chemical agents}

Exceptions to the two major sources above mentioned are compounds of dietary origin such as riboflavin (64), aflatoxin B1 (AFB1) (65) as well as the psychoactive alkaloid arecoline (66). Riboflavin (vitamin B2) has been associated with the promotion of cell migration in LC at high doses (64). In NSCLC, it caused inflammation by stimulating the production of the pro-inflammatory cytokines Interleukin 6 (IL-6), TNF- $\alpha$, and vascular endothelial growth factor (VEGF). Additionally, riboflavin upregulated the expression of the glycoprotein fibronectin, which confers resistance to LC therapy. It also upregulated the intercellular adhesion molecule 1 (ICAM-1), MMP9 and MMP-2 and promoted the activation of NF- $\kappa B$, p50, and p-p38 mitogen-activated protein kinase (MAPK) by FAK, resulting in an enhancement of migration and invasion. AFB1 is a known food contaminant and a potent liver carcinogen produced by the Aspergillus species. Cui et al. (65) demonstrated that this mycotoxin induced cell migration in NSCLC through interaction with insulin receptor substrates (IRS) 1 and 2. It was shown that AFB 1 induced the phosphorylation of non-receptor tyrosine kinase Src, an enzyme that promotes tumor cell migration and invasion, which, in turn, upregulated IRS2 
and downregulated IRS1. In a recent study (66), it was proposed that arecoline acted on the EGFR/c-Src/FAK signaling pathway via activation of MMPs, resulting in the promotion of cell migration in NSCLC. Lastly, it has been observed that the anesthetic isoflurane promoted proliferation, migration, and invasion of NSCLC cells through upregulation of the Akt-mTOR signaling pathway (67).

\section{Impairment of migration and invasion capacities of NSCLC cells upon treatment with dietary bioactive chemicals}

The search for therapeutic alternatives to reduce metastases in LC resorting to phytochemical compounds has also been the focus of many research groups. An overview of in vitro studies on migration and invasion features of NSCLC cells exposed to some of those compounds is shown in Table S3. For NSCLC cells, six groups of compounds have been often reported: (I) polyphenols non-flavonoids, (II) flavonoids, (III) bibenzyls, (IV) terpenes, (V) alkaloids and (VI) steroids. Other compounds not included in the above-mentioned groups have also been described to impair migration/invasion (VII).

\section{Polyphenols non-flavonoids}

The main polyphenols that have shown inhibitory properties on migration and/or invasion of these cells include curcumin, ephemerantol A, honokiol, mangiferin, phoyunnanin E, resveratrol, and rottlerin. Curcumin from Curcuma longa has been reported as acting on migration and invasion of NSCLC cells by reducing MMP-2/9 expression levels and inhibiting the Rho GTPase Rac1/PAK1 signaling pathway (68) as well as suppressing proliferation and migration via inhibition of epidermal growth factor receptor (EGFR) and toll-like receptor 4 (TLR4)/MyD88 pathway (69). On the other hand, ephemeranthol A, a polyphenol from Dendrobium infundibulum, was shown to inhibit cell migration by hampering the activation of FAK and Akt, and EMT by decreasing vimentin, N-cadherin, and Slug (70).

Another polyphenol that has been proposed as a potential inhibitor of migration and invasion in NSCLC is honokiol, a compound extracted from Magnolia. Indeed, a study was able to demonstrate that this compound decreased the production of prostaglandin $\mathrm{E}_{2}\left(\mathrm{PGE}_{2}\right)$ through downregulation of cyclooxygenase-2 (COX-2) expression, resulting in degradation of $\beta$-catenin and decrease of its nuclear accumulation, which is strongly associated with tumor cell migration (71). Honokiol additionally seems to prevent migration of NSCLC cells by inhibiting cellular FLICE (FADD-like IL-1 $\beta$-converting enzyme)-inhibitory protein (c-FLIP) that suppresses NF$\kappa \mathrm{B}$ and $\mathrm{N}$-cadherin/Snail signaling pathways (72). Lastly, it was also proposed that honokiol inhibited migration by causing upregulation of miR-148a-3P and miR-148a-5P (9). Mangiferin from Mangifera indica showed an inhibitory effect on proliferation, induced by lipopolysaccharide (LPS) on NSCLC cells by reducing the expression of NLR family pyrin domain containing 3 (NLRP3). It also reduced the secretion of IL-1 $\beta$, up-regulated E-cadherin, and downregulated vimentin. Importantly, mangiferin suppressed migration by decreasing the expression of $\mathrm{C}-\mathrm{X}-\mathrm{C}$ chemokine receptor type 4 (CXCR4) (30).

In another study, the suppression of $\mathrm{N}$-cadherin, vimentin, Slug and Snail, indicating inhibition of EMT, was observed in NSCLC cells after exposure to phoyunnanin E, a polyphenol from Dendrobium venustum. This compound inhibited migration and invasion by preventing the phosphorylation of FAK and Akt and decreasing the level of integrins $\alpha \mathrm{v}$ and $\beta 3$ (73).

Resveratrol inhibited proliferation, migration, and invasion of NSCLC cells by inhibiting expression of the oncogene STAT-3 (74). It has also been proposed that resveratrol inhibited EMT, migration, and invasion along with promoting senescence in LC by upregulating Rad9, an important protein in DNA damage repair which acts as a tumor suppressor (75). Lastly, rottlerin, a polyphenol from Mallotus philipinensis, was shown to hamper migration and invasion in NSCLC by inactivating the well-known oncoprotein transcriptional co-activator with PDZ-binding motif (TAZ) (76).

\section{Flavonoids}

The compounds from this large group proposed as inhibitors include: acacetin, atalantraflavone, anthocyanins, artonin E, biochanin A (BIO-A), cycloartobiloxanthone, deguelin, epicatechin-3-gallate (ECG), epigallocatechin3 -gallate (EGCG), fisetin, genistein, hesperidin, hydroxysafflor yellow A, luteolin, morin, myricetin, quercetin, Scutellaria flavonoids, and sotetsuflavone.

Acacetin was shown to inactivate mixed-lineage protein kinase 3 (MLK3), causing the suppression of p38 $\alpha$ MAPK signaling pathway. Through this mechanism, this compound caused a decrease in NF- $\mathrm{BB}$ and AP-1 activities, resulting 
in the downregulation of MMP-2/9 and u-PA expression levels (77). Atalantraflavone, in turn, is extracted from Atalantia monophylla, and was shown to inhibit migration of NSCLC cells by increasing the degradation of Twist-related protein 1 (Twist1), a transcription factor strongly associated with EMT that promotes the expression of vimentin and $\mathrm{N}$-cadherin (78).

Regarding anthocyanins, cyanidin 3-rutinoside, cyanidin 3 -glucoside, and peonidin 3-glucoside inhibited migration and invasion through the decrease in the secretion of u-PA, MMP-2/9, as well as inhibited the activation of AP-1, c-Jun, and NF- $\mathrm{\kappa B}$ and also decreased the phosphorylation of ERK1/2 (40,79). Another study by Kausar et al. (25) showed a synergistic effect of the combination of different berry anthocyanins in the inhibition of migration and invasion of NSCLC cells as well as on apoptosis through suppression of Notch and WNT pathways.

Artonin E, from Artocarpus gomezianus, was shown to inhibit migration and invasion of NSCLC cells by suppressing FAK, Akt, and guanosine-5'-triphosphatase cell division cycle-42 (CDC42) (80). Cycloartobiloxanthone, also from Artocarpus gomezianus, had a similar effect on FAK and CDC42 (81). Tungsukruthai et al. (81) additionally demonstrated that this compound hindered EMT by upregulating E-cadherin and decreasing integrins $\alpha 5, \alpha$, and 33 . BIO-A, present in chickpeas, suppressed migration and proliferation of NSCLC via downregulation of VEGF and MMP-2 and reduction of the expression of proliferation marker Ki-67, as well as by inducing apoptosis through the activation of caspases- 3 and 9 (82).

Two different studies have proposed that deguelin acts as an inhibitor of migration and invasion. This compound inhibited NF- $\kappa \mathrm{B}, \mathrm{Akt}$, Ras, and PKC signaling pathways, causing a decrease in u-PA and MMP-2/9 expression levels, thus hampering migration and invasion (83). In another study, the authors demonstrated that deguelin inhibited these processes through the suppression of the FAK/Src/ Paxillin signaling pathway by preventing the activation of Cathepsin Z (CtsZ) (84).

Epigallocatechin-3-gallate (EGCG), and epicatechin-3gallate (ECG), two flavonoids present in green tea, showed an inhibitory action in TGF- $\beta$-induced EMT and upregulated the expression of E-cadherin. EGCG suppressed the expression of transcription factors involved in EMT such as zinc finger E-box-binding homeobox 1 (ZEB1), Snail, Slug, and Twist and reduced the activation of Smad2 and ERK1/2 (85). ECG, in turn, suppressed MMP-2, fibronectin and p-FAK (46).
Several studies have investigated the effect of fisetin on NSCLC cells. In general, it was observed that this flavonoid inhibited adhesion, migration and invasion $(4,48)$ by downregulating the expression of MMP-2, $\mathrm{u}-\mathrm{PA}$, Twist, N-cadherin, and c-Jun and upregulating E-cadherin and ZO-1. It was reported that fisetin inhibited the phosphorylation of ERK1/2 and also downregulated proteins involved in the induction of EMT, such as STAT3, EGFR, and NF- $\mathrm{KB}(28,86)$.

Genistein, a flavonoid from soy, was able to suppress migration and invasion of lung cancer stem-like cells (LCSLCs) derived from NSCLC cells by regulating the expression of manganese superoxide dismutase (MnSOD) and Forkhead box protein M1 (FoxM1) (87). Hesperidin can be extracted from citrus fruits and a study proposed that its inhibitory properties on migration and invasion occur via mediation of the SDF-1/CXCR-4 signaling cascade by reducing the secretion of stromal cell-derived factor 1 (SDF-1), resulting in a decrease in CXCR-4, p-p65, p-IкB, and p-Akt. Hesperidin also inhibited EMT by decreasing levels of MMP-9 and Vimentin (88).

In turn, hydroxysafflor yellow A suppressed migrationrelated PI3K/Akt/mTOR and ERK/MAPK signaling pathways (89). Luteolin, a flavonoid present in various plants, inhibited migration through hampering stress fiber formation, a process essential for cell motility (90). Furthermore, morin decreased migration by downregulating miR-135b, preventing the repression of the CCNG2 tumor suppressor gene (10). A study showed that myricetin could inhibit migration by suppressing the FAK/ERK signaling pathway which, consequently, caused a decrease in MMP-2/9 expression levels (91). Quercetin, a well-known flavonoid, was shown to reduce metastasis by inhibiting Snail, and thus inhibiting Akt activation together with suppression of the ADAM9 pathway (31). Oroxylin A (OA), a flavonoid from Scutellaria radix, also inhibited Snail through the suppression of the ERK/GSK-3 $\beta$ signaling pathway, and also reduced vimentin and increased E-cadherin expressions (92).

Other flavonoids from Scutellaria, have also been studied, i.e., baicalein $(93,94)$, baicalin, and wogonin $(94)$, and were suggested to suppress cell invasion and EMT by increasing E-cadherin and decreasing vimentin expression. More recently, it was also proposed that this suppression together with blockage of angiogenesis was achieved through inhibition of alpha-7 nicotinic acetylcholine receptor (a7nAChR). This effect led to the activation of Rap1, a protein from the Ras family of GTPase and associated with cell adhesion and integrin-mediated processes, dephosphorylation of Akt and 
Src, leading to a decrease in Id 1 expression, a transcription factor that mediates proliferation, angiogenesis, EMT and invasion (94). Lastly, a study focusing on sotetsuflavone demonstrated that this flavonoid could inhibit migration and invasion of NSCLC cells (95).

\section{Bibenzyls}

The chemicals included in this group are: chrysotobibenzyl, gigantol, moscatilin, riccardin D and 4,5,40-trihydroxy3,30-dimethoxybibenzyl (TDB). Chrysotobibenzyl, from Dendrobium pulchellum, caused a decrease in integrins, such as $\alpha v, \beta 1$, and $\beta 3$, via downregulation of caveolin-1 (Cav-1), resulting in the inhibition of migration (27). Likewise, gigantol from Dendrobium draconis also inhibited migration by downregulating Cav-1, resulting in a decrease in the activation of Akt and CDC42 expression. This effect occurred via reduction in EMT markers including Slug, N-cadherin, and vimentin $(29,96)$. Furthermore, moscatilin inhibited invasion and migration through the reduction of endogenous ROS and decreased activation of FAK and Akt, proteins that are needed for activation of ERK1/2 and of CDC42, respectively (97). Another bibenzyl that has been proposed is riccardin D, which inhibited migration and invasion via suppression of the ERK1/2 signaling pathway, causing a decrease in MMP-2/9 levels (98). To conclude, Chaotham et al. (39) demonstrated that TDB, a bibenzyl from Dendrobium ellipsophyllum, acted on migration and invasion by downregulating p-FAK, activated Ras-related C3 botulinum toxin substrate 1 (Rac1-GTP) and CDC42, and, similarly to chrysotobibenzyl, by decreasing integrins $\alpha 4, \alpha v, \beta 1$, and $\beta 5$.

\section{Terpenes}

The terpenes that have been proposed as potential inhibitors of migration and invasion of NSCLC cells are: actein, alisol $\mathrm{B}$, betulin, frondoside $\mathrm{A}$, nagilactone $\mathrm{E}$, triptolide, and ursolic acid. It was demonstrated that actein inhibits migration and invasion but the underlying mechanism is yet to be determined (99). Likewise, frondoside A was able to suppress these two phenomena in a time and dose-dependent manner (100). Alisol B has shown an ability to reduce cell migration and invasion, and the underlying mechanisms seem to consist, at least partially, of inhibiting the PI3K/Akt/mTOR signaling pathway (101). Furthermore, betulin, a triterpene from Quercus incana, suppressed migration and invasion by reducing MMP-2/9 expression levels (102). In addition, nagilactone $\mathrm{E}$ acts as a migration and invasion inhibitor as observed in TGF$\beta 1$-stimulated NSCLC cells. Its mechanism consisted of the inhibition of EMT via the suppression of Smad2 and Smad 3 activation and translocation to the nucleus. This compound could also inhibit the up-regulation of MMP$2 / 9$, integrins $\alpha \mathrm{v}$ and $\beta 3$, as well as the phosphorylation of FAK (103). Similarly, triptolide also affected FAK, reducing its expression levels and, thus, causing a reduction in migration (36). Finally, ursolic acid has been proposed as an inhibitor of migration and proliferation as well as an inducer of apoptosis due to its ability to downregulate the $\beta$-catenin/TCF4/CT45A2 signaling pathway (104).

\section{Alkaloids}

The alkaloids that have been shown to inhibit migration and invasion are: daurinoline, krukovine, and oxymatrine. Daurinoline, an alkaloid from the roots of Menispermum dauricum, reversed EMT by causing an increase in E-cadherin and a decrease in vimentin and MMP2 expression levels (105). Krukovine, from the bark of Abuta grandifolia, only inhibited cell migration through the suppression of Akt, ERK, phosphoinositide 3-kinases (PI3K), p70sk6k, RAF proto-oncogene serine/threonineprotein kinase (C-RAF) and mTOR (106). Lastly, two studies have demonstrated inhibitory functions of oxymatrine in NSCLC cell migration and invasion. In the first study, the anti-migratory effect of this compound was demonstrated but the underlying mechanisms were not explored (107). In the second study, it was observed that this inhibition was caused by the up-regulation of miR-520, causing VEGF inhibition (11).

\section{Steroids}

Three compounds have been proposed in this group: bufalin, cardenolides, and ophiopogonin B. The effects of bufalin on migration and invasion of NSCLC cells have been investigated in three different studies. In the first study, it was shown that bufalin suppressed migration in TGF- $\beta$ induced NSCLC cells by inhibiting the phosphorylation of Smad 2 and Smad3 and by downregulating Twist 2 and zinc finger E-box binding homeobox 2 (ZEB2) together with the suppression of TGF- $\beta$ receptor I (T $\beta R I)$ and TGF- $\beta$ receptor II (T $\beta$ RII) (108). In a second study, it was demonstrated that this compound also suppressed migration and invasion by reducing the levels of MMP-2/9, PKC, NF$\kappa \mathrm{B}, \mathrm{PI} 3 \mathrm{~K}, \mathrm{ERK}$, growth factor receptor-bound protein 2 
(GRB2), phosphorylated c-Jun NH2-terminal kinase (JNK), p-Akt and phosphorylated p38 (26). Huang et al. (109) obtained similar results regarding MMP-2 and ERK, and additionally found that bufalin also caused a reduction in Ras/Rac guanine nucleotide exchange factor 1 (SOS-1), Rho A, p-FAK, and E-cadherin. However, contrary to the results obtained by Wu et al. (26), this latest study found that bufalin increased phosphorylated $\mathrm{p} 38$, phosphorylated JNK, and Nf-кBp65 (109).

Regarding cardenolides, two different compounds, digitoxigenin monodigitoxoside (DGX) and convallotoxin (CON) have been studied. Both compounds demonstrated to have anti-migratory and anti-invasive effects on NSCLC cells by, similarly to bufalin, reducing the levels of MMP2/9 and p-FAK (110). To conclude, ophiopogonin B, extracted from Radix Ophiopogon Faponicus, was able to inhibit migration and invasion by increasing the levels of E-cadherin and tight junction protein Zonula occludens-1 (ZO-1), and reducing the expression of $\mathrm{N}$-cadherin, Slug, Snail, and ZEB1 as well as suppressing the EphA2/Akt signaling pathway (111).

\section{Other chemical agents}

Other compounds have also been suggested as inhibitors of migration and/or invasion in NSCLC cells, such as coix polysaccharides (112), cordycepin (113), dihydroaustrasulfone alcohol (114), esculetin (115), evodiamine (116), ganoderan (117), glycyrol (118), goniothalamin (119), isothiocyanates (12,120-122), magnolin (123), methylene chloride (32), renieramycin $M$ (124), salidroside (125), sodium new houttuyfonate (126), $\Delta^{9}$-Tetrahydrocannabinol (THC) (127), and thymoquinone (45). These compounds were mostly associated with the downregulation of STAT3 and ERK1/2 or the activation of ERK5 signaling pathways. Decreases in MMP-2 and 9, VEGF, FAK, Snail, and vimentin expression, and an increase in E-cadherin and ZO-1 were also observed. Isothiocyanates, in particular, have been the focus of numerous migration and invasion studies. In addition to the mechanisms referred above, isothiocyanates such as sulforaphane and its derivatives sulforaphane-cysteine (SFN-Cys) and sulforaphane-Nacetyl-L-cysteine (SFN-NAC), were shown to act via claudins dysfunction and inhibition of autolysosome through microtubules (120) as well as suppression of the GSK3 $\beta$ / $\beta$-catenin signaling pathway (12). On the other hand, the underlying mechanisms through which evodiamine (116), glycyrol (118), renieramycin M (124) and THC (127) achieved these effects are yet to be determined (127), since the output from the methodologies used was only a decrease in migration/invasion.

\section{Conclusions and future perspectives}

LC corresponds to a group of cancer diseases with poor prognosis, being this outcome clearly associated with the highly migratory and invasive behavior of these malignant cells. Understanding the underlying mechanisms involved in these features is crucial for the knowledge of putative risk factors in NSCLC as well as for the development of new therapeutic alternatives.

In this report, a relatively large number of in vitro studies were considered, as seen in Table S1. It is clear that the vast majority of the reports on the assessment of migration/ invasion of NSCLC cells in vitro resorted to the woundhealing migration assay and the transwell invasion and migration assays. Still, some other methods have been employed, namely the fence assay, the time-lapse cell tracking, the cell exclusion assay and the spheroid migration assay for migration evaluation and spheroid gel invasion and cell tracking for invasion.

These assays have allowed better insights on the effects of certain contaminants on NSCLC development and progression. It has been proposed that several cigarette smoke contaminants have a key role in promoting migration and/or invasion, including NNK $(53,54)$ and $\mathrm{B}(\mathrm{a}) \mathrm{P}(55,56)$, as well as some air pollutants such as Oxy-PAHs (24). Such studies are relevant to understand the development and progression of carcinogenesis and also to bring awareness to risks that should be avoided. On the other hand, a great variety of plant-extracted compounds, such as various polyphenols non-flavonoids, flavonoids, and bibenzyls, among others, have been investigated and exhibited inhibitory functions on migration and invasion of NSCLC in vitro. These could potentially represent new opportunities for innovative therapeutic strategies to prevent or hamper metastases in LC. A compilation of compounds that display either pro or antimigration and invasion capabilities in NSCLC cells in vitro is depicted in Figure 1.

The studies discussed in this review can indeed play an important role, either directly or indirectly, in the prevention and prognosis of LC in the future. Nevertheless, one shortcoming of the drug development process underlying these issues is the lack of predictive, pathophysiologically relevant preclinical models of invasive tumor phenotypes. Indeed, most of the in vitro experiments 


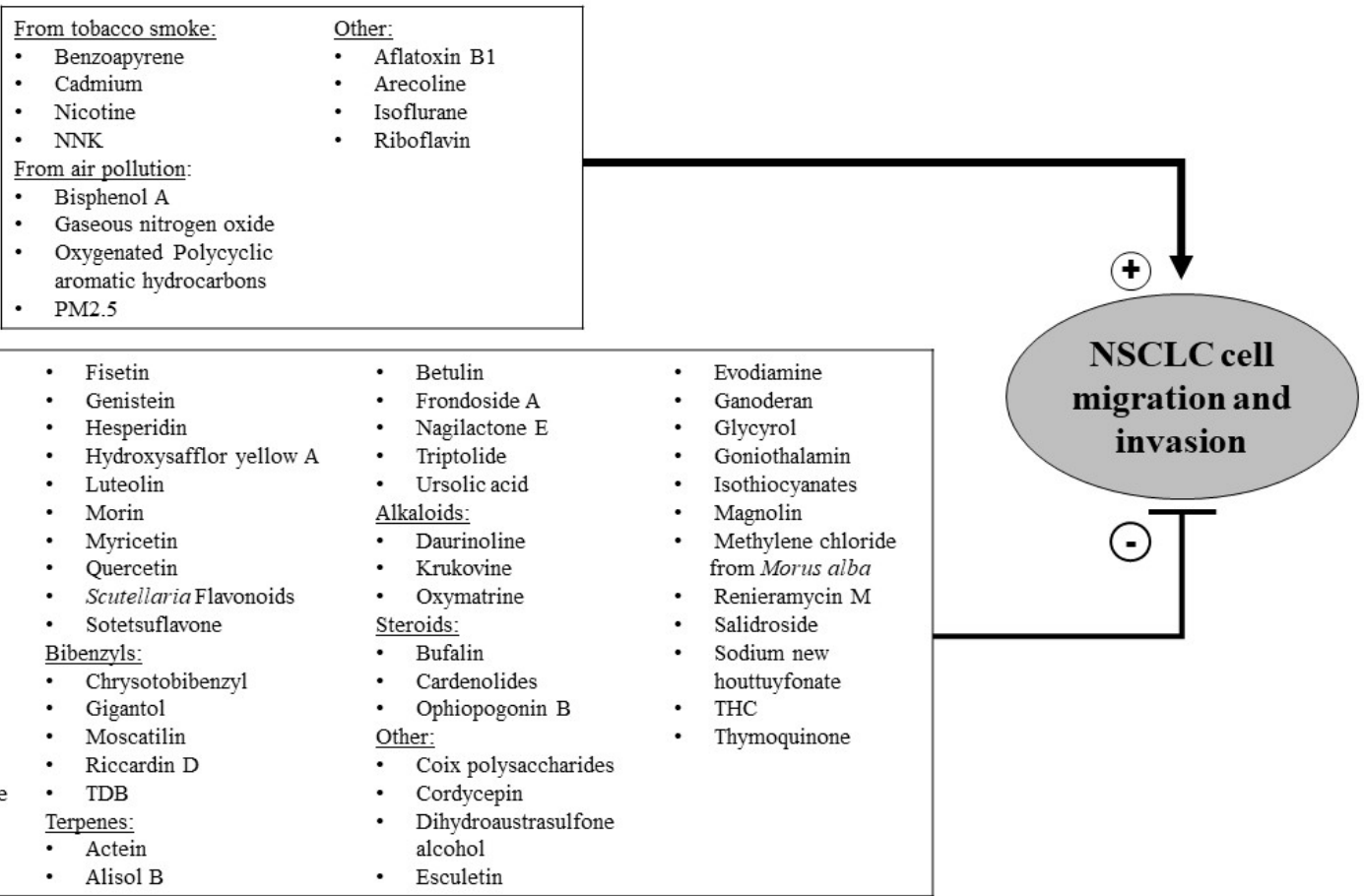

Figure 1 Summary of contaminants/carcinogens and phytochemical compounds that exhibit promoting (+) or inhibitory (-) functions in NSCLC migration and invasion. ECG, Epicatechin-3-gallate; EGCG, Epigallocatechin-3-gallate; NNK, nitrosamine 4-(methylnitrosamino)-1-(3-pyridyl)-1-butanone; PM2.5, particulate matters with less than $2.5 \mu \mathrm{m}$ of diameter; TDB, 4,5,40-trihydroxy3,30-dimethoxybibenzyl; THC, $\Delta^{9}$-Tetrahydrocannabinol.

employ conventional 2D cell culture methods that are not able to closely mimic the in vivo tumor microenvironment and cancer cell interactions. Thus, it is important that additional in vitro methodologies should be explored to consider the interactions between cancer cells and stroma, and between the tumor and tissue specific cells. 3D migration and invasion models such as spheroid migration or spheroid gel invasion assays have been used only in a few NSCLC studies $(21,23,47)$. Using multicellular spheroid models would be more feasible to activate migration and invasion mechanisms that are not clearly observed in simpler models, since cancer cells face a greater number of obstacles, such as hypoxia and ECM (128). Additionally, other assays such as the spheroid/monodispersed cell invasion assay and the spheroid confrontation assay will provide a better evaluation of tumor invasion by representing the invasive capacity of cancer cells into a tissue that consists of an assortment of different cells (5). In addition, circulating tumor cell (CTC) clusters in the blood of lung cancer patients, which have greater potential to metastasize and have more survival advantages than single CTC cells, should be taken into consideration $(129,130)$. Spheroid models could be proven beneficial for the study of these cells in vitro (129). Lastly, microfluidic devices facilitate the assessment of cancer cells' response to different external physical factors, such as ECM density, that affect the ability of cells to migrate and invade. These devices also enable the use of chemotaxis in combination with haptotaxis signals, simulating different migratory behaviors. The possibility to use different cell types in the same device contributes to a better understanding of the influence of multiple cells in cancer cell migration $(131,132)$. Microfluidic technology could prove to be extremely useful in the study of cell communication, cell-to-cell interactions and tumor cell interactions with ECM in NSCLC and the influence of those factors on migration, invasion, and metastasis processes.

Furthermore, the use of animal models in the study of metastasis to better mimic tumor microenvironment and clarify the tumor development process should be explored. 
These models could include transgenic mouse models, human tumor xenograft, orthotopic lung cancer models or induced lung tumors (133). Each animal model can resemble only a fraction of the spectrum of a metastasis's molecular mechanism, thus, it is necessary to use multiple animal models that complement each other, allowing for an accurate study of this process.

In conclusion, the information gathered in this review will surely be updated in the next years, constituting an interesting topic for discussion in NSCLC. Moreover, the impact of many other xenobiotics will be revealed using in vitro migration and invasion assays. Albeit many of the findings and conclusions resultant from these experiments should be further confirmed or reinforced using more sophisticated in vitro models and/or adequate in vivo experiments, they clearly constitute a valuable approach that should be considered.

\section{Acknowledgments}

Funding: This work was supported by Fundação para a Ciência e a Tecnologia (FCT), through funding (UIDB/04138/2020, UIDP/04138/2020) to the Research Institute for Medicines (iMed.ULisboa) and (UIDB/04567/2020, UIDP/04567/2020) to the Research Center for Biosciences \& Health Technologies (CBIOS); Universidade Lusófona/ Instituto Lusófono de Investigação e Desenvolvimento (ILIND) Grant Programme (FIPID 2019/2020, PTDC/MED-TOX/29183/2017). R.R. reports grants from La Caixa Foundation and from the Spanish Association Against Cancer (PROYE18012ROSE).

\section{Footnote}

Reporting Checklist: The authors have completed the Narrative Review reporting checklist. Available at http:// dx.doi.org/10.21037/tlcr-21-121

Conflicts of Interest: All authors have completed the ICMJE uniform disclosure form (available at http://dx.doi. org/10.21037/tlcr-21-121). RR serves as an Editor-in-Chief of Translational Lung Cancer Research from Jun 2019 to May 2022. The other authors have no conflicts of interest to declare.

Ethical Statement: The authors are accountable for all aspects of the work in ensuring that questions related to the accuracy or integrity of any part of the work are appropriately investigated and resolved.

Open Access Statement: This is an Open Access article distributed in accordance with the Creative Commons Attribution-NonCommercial-NoDerivs 4.0 International License (CC BY-NC-ND 4.0), which permits the noncommercial replication and distribution of the article with the strict proviso that no changes or edits are made and the original work is properly cited (including links to both the formal publication through the relevant DOI and the license). See: https://creativecommons.org/licenses/by-nc-nd/4.0/.

\section{References}

1. Bray F, Ferlay J, Soerjomataram I, et al. Global cancer statistics 2018: GLOBOCAN estimates of incidence and mortality worldwide for 36 cancers in 185 countries. CA Cancer J Clin 2018;68:394-424.

2. Siegel RL, Miller KD, Jemal A. Cancer statistics, 2020. CA Cancer J Clin 2020;70:7-30.

3. Chanvorachote P, Chamni S, Ninsontia C, et al. Potential anti-metastasis natural compounds for lung cancer. Anticancer Res 2016;36:5707-17.

4. Tabasum S, Singh RP. Fisetin suppresses migration, invasion and stem-cell-like phenotype of human non-small cell lung carcinoma cells via attenuation of epithelial to mesenchymal transition. Chem Biol Interact 2019;303:14-21.

5. Kramer N, Walzl A, Unger C, et al. In vitro cell migration and invasion assays. Mutat Res 2013;752:10-24.

6. Popper HH. Progression and metastasis of lung cancer. Cancer Metastasis Rev 2016;35:75-91.

7. Zhu T, Bao X, Chen M, et al. Mechanisms and Future of Non-Small Cell Lung Cancer Metastasis. Front Oncol 2020;10:585284.

8. Xie S, Wu Z, Qi Y, et al. The metastasizing mechanisms of lung cancer: Recent advances and therapeutic challenges. Biomed Pharmacother 2021;138:111450.

9. Zhang J, Zhang Y, Shen W, et al. Cytological effects of honokiol treatment and its potential mechanism of action in non-small cell lung cancer. Biomed Pharmacother 2019;117:109058.

10. Yao D, Cui H, Zhou S, et al. Morin inhibited lung cancer cells viability, growth, and migration by suppressing miR$135 \mathrm{~b}$ and inducing its target CCNG2. Tumour Biol 2017;39:1010428317712443.

11. Zhou W, Wu Y, Pan M, et al. Proliferation and Migration of Lung Cancer Could be Inhibited by Oxymatrine 
through the Regulation for miR-520/VEGF. Am J Chin Med 2019;47:865-78.

12. Wang DX, Zou YJ, Zhuang X, et al. Sulforaphane suppresses EMT and metastasis in human lung cancer through miR-616-5p-mediated GSK3 $\beta / \beta$-catenin signaling pathways. Acta Pharmacol Sin 2017;38:241-51.

13. Puisségur MP, Mazure NM, Bertero T, et al. miR-210 is overexpressed in late stages of lung cancer and mediates mitochondrial alterations associated with modulation of HIF-1 activity. Cell Death Differ 2011;18:465-78.

14. Friedl P, Wolf K. Plasticity of cell migration: A multiscale tuning model. J Cell Biol 2010;188:11-9.

15. Thiery JP. Epithelial-mesenchymal transitions in tumor progression. Nat Rev Cancer 2002;2:442-54.

16. Trepat X, Chen Z, Jacobson K. Cell migration. Compr Physiol 2012;2:2369-92.

17. Friedl P, Gilmour D. Collective cell migration in morphogenesis, regeneration and cancer. Nat Rev Mol Cell Biol 2009; 10:445-57.

18. Cao Y, Wang X, Li Y, et al. Extracellular and macropinocytosis internalized ATP work together to induce epithelial-mesenchymal transition and other early metastatic activities in lung cancer. Cancer Cell Int 2019;19:254.

19. Huang WT, Chong IW, Chen HL, et al. Pigment epithelium-derived factor inhibits lung cancer migration and invasion by upregulating exosomal thrombospondin 1 . Cancer Lett 2019;442:287-98.

20. Korsnes MS, Korsnes R. Single-cell tracking of A549 lung cancer cells exposed to a marine toxin reveals correlations in pedigree tree profiles. Front Oncol 2018;8:260.

21. Müller B, Bovet M, Yin Y, et al. Concomitant expression of far upstream element (FUSE) binding protein (FBP) interacting repressor (FIR) and its splice variants induce migration and invasion of non-small cell lung cancer (NSCLC) cells. J Pathol 2015;237:390-401.

22. Giatromanolaki A, Kalamida D, Sivridis E, et al. Increased expression of transcription factor EB (TFEB) is associated with autophagy, migratory phenotype and poor prognosis in non-small cell lung cancer. Lung Cancer 2015;90:98-105.

23. Rao JS, Gondi C, Chetty C, et al. Inhibition of invasion, angiogenesis, tumor growth, and metastasis by adenovirus-mediated transfer of antisense uPAR and MMP-9 in non-small cell lung cancer cells. Mol Cancer Ther 2005;4:1399-408.

24. Li D, Yun Y, Gao R. Oxygenated Polycyclic aromatic hydrocarbons (Oxy-PAHs) facilitate lung cancer metastasis by epigenetically regulating the epithelial-to-mesenchymal transition (EMT). Environ Pollut 2019;255:113261.

25. Kausar H, Jeyabalan J, Aqil F, et al. Berry anthocyanidins synergistically suppress growth and invasive potential of human non-small-cell lung cancer cells. Cancer Lett 2012;325:54-62.

26. Wu SH, Hsiao Y'T, Kuo CL, et al. Bufalin Inhibits NCI-H460 human lung cancer cell metastasis in vitro by inhibiting MAPKs, MMPs, and NF- $\kappa$ B Pathways. Am J Chin Med 2015;43:1247-64.

27. Petpiroon N, Bhummaphan N, Tungsukruthai S, et al. Chrysotobibenzyl inhibition of lung cancer cell migration through Caveolin-1-dependent mediation of the integrin switch and the sensitization of lung cancer cells to cisplatin-mediated apoptosis. Phytomedicine 2019;58:152888.

28. Liao YC, Shih YW, Chao CH, et al. Involvement of the ERK Signaling Pathway in Fisetin Reduces Invasion and Migration in the Human Lung Cancer Cell Line A549. J Agric Food Chem 2009;57:8933-41.

29. Charoenrungruang S, Chanvorachote P, Sritularak B, et al. Gigantol, a bibenzyl from Dendrobium draconis, inhibits the migratory behavior of non-small cell lung cancer cells. J Nat Prod 2014;77:1359-66.

30. Lin YS, Tsai KL, Chen JN, et al. Mangiferin inhibits lipopolysaccharide-induced epithelial-mesenchymal transition (EMT) and enhances the expression of tumor suppressor gene PER1 in non-small cell lung cancer cells. Environ Toxicol 2020;35:1070-81.

31. Chang JH, Lai SL, Chen WS, et al. Quercetin suppresses the metastatic ability of lung cancer through inhibiting Snail-dependent Akt activation and Snail-independent ADAM9 expression pathways. Biochim Biophys Acta Mol Cell Res 2017;1864:1746-58.

32. Min TR, Park HJ, Park MN, et al. The root bark of morus alba 1. Suppressed the migration of human non-smallcell lung cancer cells through inhibition of epithelialmesenchymal transition mediated by STAT3 and Src. Int J Mol Sci 2019;20:2244.

33. Chen WL, Kuo KT, Chou TY, et al. The role of cytochrome c oxidase subunit $\mathrm{Va}$ in non-small cell lung carcinoma cells: Association with migration, invasion and prediction of distant metastasis. BMC Cancer 2012;12:273.

34. Zhang KS, Chen HQ, Chen YS, et al. Bisphenol

A stimulates human lung cancer cell migration via upregulation of matrix metalloproteinases by GPER/ EGFR/ERK1/2 signal pathway. Biomed Pharmacother 2014;68:1037-43. 
35. Zhai H, Pan T, Yang H, et al. Cadmium induces A549 cell migration and invasion by activating ERK. Exp Ther Med 2019;18:1793-9.

36. Reno TA, Kim JY, Raz DJ. Triptolide inhibits lung cancer cell migration, invasion, and metastasis. Ann Thorac Surg 2015;100:1817-24.

37. Luo H, Li Z, Ge H, et al. HMGA2 upregulation mediates Cd-induced migration and invasion in A549 cells and in lung tissues of mice. Chem Biol Interact 2017;277:1-7.

38. Lv W, Sui L, Yan X, et al. ROS-dependent Atg4 upregulation mediated autophagy plays an important role in Cd-induced proliferation and invasion in A549 cells. Chem Biol Interact 2018;279:136-44.

39. Chaotham C, Chanvorachote P. A bibenzyl from Dendrobium ellipsophyllum inhibits migration in lung cancer cells. J Nat Med 2015;69:565-74.

40. Chen PN, Chu SC, Chiou HL, et al. Mulberry anthocyanins, cyanidin 3-rutinoside and cyanidin 3-glucoside, exhibited an inhibitory effect on the migration and invasion of a human lung cancer cell line. Cancer Lett 2006;235:248-59.

41. Marshall J. Transwell@ Invasion Assays. In: Wells C, Parsons M. (eds) Cell Migration. Methods in Molecular Biology (Methods and Protocols) 2011;769:97-110.

42. Cory G. Scratch-Wound Assay. In: Wells C, Parsons M. (eds) Cell Migration. Methods in Molecular Biology (Methods and Protocols) 2011;769:25-30.

43. Grada A, Otero-Vinas M, Prieto-Castrillo F, et al. Research Techniques Made Simple: Analysis of Collective Cell Migration Using the Wound Healing Assay. J Invest Dermatol 2017;137:e11-6.

44. Stamm A, Reimers K, Strauß S, et al. In vitro wound healing assays - State of the art. BioNanoMaterials 2016;17:79-87.

45. Yang J, Kuang XR, Lv PT, et al. Thymoquinone inhibits proliferation and invasion of human nonsmallcell lung cancer cells via ERK pathway. Tumour Biol 2015;36:259-69.

46. Huang SF, Horng CT, Hsieh YS, et al. Epicatechin3 -gallate reverses TGF- $\beta 1$-induced epithelial-tomesenchymal transition and inhibits cell invasion and protease activities in human lung cancer cells. Food Chem Toxicol 2016;94:1-10.

47. Li X, Ishihara S, Yasuda M, et al. Lung Cancer Cells That Survive Ionizing Radiation Show Increased Integrin $\alpha 2 \beta 1$ - and EGFR-Dependent Invasiveness. PLoS One 2013;8:e70905.

48. Wang J, Huang S. Fisetin inhibits the growth and migration in the A549 human lung cancer cell line via the ERK1/2 pathway. Exp Ther Med 2018;15:2667-73.

49. Hecht SS. Tobacco smoke carcinogens and lung cancer. J Natl Cancer Inst 1999;91:1194-210.

50. Dasgupta P, Rizwani W, Pillai S, et al. Nicotine induces cell proliferation, invasion and epithelial- mesenchymal transition in a variety of human cancer cell lines. Int J Cancer 2009; 124:36-45.

51. Nair S, Bora-Singhal N, Perumal D, et al. Nicotinemediated invasion and migration of non-small cell lung carcinoma cells by modulating STMN3 and GSPT1 genes in an ID1-dependent manner. Mol Cancer 2014;13:173.

52. Zhao H, Wang Y, Ren X. Nicotine promotes the development of non-small cell lung cancer through activating LINC00460 and PI3K/Akt signaling. Biosci Rep 2019;39:1-10.

53. Shen J, Xu L, Owonikoko TK, et al. NNK promotes migration and invasion of lung cancer cells through activation of c-Src/PKC1/FAK loop. Cancer Lett 2012;318:106-13.

54. Wang Y, Shi L, Li J, et al. Involvement of twist in NNK exposure-promoted lung cancer cell migration and invasion. Toxicol In Vitro 2020;63:104740.

55. Zhang J, Chang L, Jin H, et al. Benzopyrene promotes lung cancer A549 cell migration and invasion through upregulating cytokine IL8 and chemokines CCL2 and CCL3 expression. Exp Biol Med (Maywood) 2016;241:1516-23.

56. Zhao G, Wang Z, Huang Y, et al. Effects of Benzoapyrene on migration and invasion of lung cancer cells functioning by TNF- $\alpha$. J Cell Biochem 2018;119:6492-500.

57. Wang Y, Shi L, Li J, et al. The roles of TG-interacting factor in cadmium exposure-promoted invasion and migration of lung cancer cells. Toxicol In Vitro 2019;61:104630.

58. Fujiki K, Inamurai H, Miyayamai T, et al. Involvement of Notch1 signaling in malignant progression of A549 cells subjected to prolonged cadmium exposure. J Biol Chem 2017;292:7942-53.

59. Deng X, Feng N, Zheng M, et al. PM2.5 exposure-induced autophagy is mediated by lncRNA loc146880 which also promotes the migration and invasion of lung cancer cells. Biochim Biophys Acta - Gen Subj 2017;1861:112-25.

60. Lin H, Zhang X, Feng N, et al. LncRNA LCPAT1 mediates smoking/ Particulate matter 2.5-induced cell autophagy and epithelial-mesenchymal transition in lung cancer cells via RCC2. Cell Physiol Biochem 2018;47:1244-58.

61. Yang B, Chen D, Zhao H, et al. The effects for PM2.5 
exposure on non-small-cell lung cancer induced motility and proliferation. Springerplus 2016;5:2059.

62. Chen JH, Lin HH, Chiang TA, et al. Gaseous nitrogen oxide promotes human lung cancer cell line A549 migration, invasion, and metastasis via inos-mediated MMP-2 production. Toxicol Sci 2008;106:364-75.

63. Ryszawy D, Pudełek M, Kochanowski P, et al. High bisphenol A concentrations augment the invasiveness of tumor cells through Snail-1/Cx43/ERR $\gamma$-dependent epithelial-mesenchymal transition. Toxicol In Vitro 2020;62:104676.

64. Yang HT, Chao PC, Yin MC. Riboflavin at High Doses Enhances Lung Cancer Cell Proliferation, Invasion, and Migration. J Food Sci 2013;78:H343-9.

65. Cui A, Hua H, Shao T, et al. Aflatoxin B1 induces Src phosphorylation and stimulates lung cancer cell migration. Tumour Biol 2015;36:6507-13.

66. Chang CH, Chen MC, Chiu TH, et al. Arecoline promotes migration of A549 lung cancer cells through activating the EGFR/SRC/FAK pathway. Toxins (Basel) 2019;11:1-15.

67. Zhang $W$, Shao X. Isoflurane promotes non-small cell lung cancer malignancy by activating the akt-mammalian target of rapamycin (mTOR) signaling pathway. Med Sci Monit 2016;22:4644-50.

68. Chen QY, Zheng Y, Jiao DM, et al. Curcumin inhibits lung cancer cell migration and invasion through Rac1-dependent signaling pathway. J Nutr Biochem 2014;25:177-85.

69. Zhang L, Tao X, Fu Q, et al. Curcumin inhibits cell proliferation and migration in NSCLC through a synergistic effect on the TLR4/MyD88 and EGFR pathways. Oncol Rep 2019;42:1843-55.

70. Nonpanya N, Prakhongcheep O, Petsri K, et al. Ephemeranthol A suppresses epithelial to mesenchymal transition and FAK-Akt signaling in lung cancer cells. Anticancer Res 2020;40:4989-99.

71. Singh T, Katiyar SK. Honokiol Inhibits Non-Small Cell Lung Cancer Cell Migration by Targeting PGE2Mediated Activation of $\beta$-Catenin Signaling. PLoS One 2013;8:e60749.

72. Lv XQ, Qiao XR, Su L, et al. Honokiol inhibits EMTmediated motility and migration of human non-small cell lung cancer cells in vitro by targeting c-FLIP. Acta Pharmacol Sin 2016;37:1574-86.

73. Petpiroon N, Sritularak B, Chanvorachote P. Phoyunnanin E inhibits migration of non-small cell lung cancer cells via suppression of epithelial-to-mesenchymal transition and integrin $\alpha \mathrm{v}$ and integrin $\beta 3$. BMC Complement Altern Med 2017;17:553.

74. Li X, Wang D, Zhao QC, et al. Resveratrol Inhibited Non-small Cell Lung Cancer Through Inhibiting STAT-3 Signaling. Am J Med Sci 2016;352:524-30.

75. Chen KY, Chen CC, Chang YC, et al. Resveratrol induced premature senescence and inhibited epithelialmesenchymal transition of cancer cells via induction of tumor suppressor Rad9. PLoS One 2019;14:e0219317.

76. Zhao Z, Zheng N, Wang L, et al. Rottlerin exhibits antitumor activity via down-regulation of TAZ in nonsmall cell lung cancer. Oncotarget 2017;8:7827-38.

77. Chien ST, Lin SS, Wang CK, et al. Acacetin inhibits the invasion and migration of human non-small cell lung cancer A549 cells by suppressing the p38 $\alpha$ MAPK signaling pathway. Mol Cell Biochem 2011;350:135-48.

78. Yuan T, Ling F, Wang Y, et al. A natural product atalantraflavone inhibits non-small cell lung cancer progression via destabilizing Twist1. Fitoterapia 2019;137:104275.

79. Ho ML, Chen PN, Chu SC, et al. Peonidin 3-glucoside inhibits lung cancer metastasis by downregulation of proteinases activities and MAPK pathway. Nutr Cancer 2010;62:505-16.

80. Plaibua K, Pongrakhananon V, Chunhacha P, et al. Effects of artonin $\mathrm{E}$ on migration and invasion capabilities of human lung cancer cells. Anticancer Res 2013;33:3079-88.

81. Tungsukruthai S, Sritularak B, Chanvorachote P. Cycloartobiloxanthone inhibits migration and invasion of lung cancer cells. Anticancer Res 2017;37:6311-9.

82. Lai X, Li Y, Gao M. Biochanin A regulates the growth and migration of NSCLC through suppressing the VEGF/ VEGFR2 signaling pathway. Oncol Res Featur Preclin Clin Cancer Ther 2018;1-22.

83. Hsiao YT, Fan MJ, Huang AC, et al. Deguelin Impairs Cell Adhesion, Migration and Invasion of Human Lung Cancer Cells through the NF- $\kappa$ B Signaling Pathways. Am J Chin Med 2018;46:209-29.

84. Li W, Yu X, Ma X, et al. Deguelin attenuates non-small cell lung cancer cell metastasis through inhibiting the CtsZ/FAK signaling pathway. Cell Signal 2018;50:131-41.

85. Liu LC, Tsao TCY, Hsu SR, et al. EGCG inhibits transforming growth factor- $\beta$-mediated epithelial-tomesenchymal transition via the inhibition of $\operatorname{smad} 2$ and Erk1/2 signaling pathways in nonsmall cell lung cancer cells. J Agric Food Chem 2012;60:9863-73.

86. Klimaszewska-Wiśniewska A, Hałas-Wiśniewska M, Grzanka A, et al. Evaluation of anti-metastatic potential 
of the combination of fisetin with paclitaxel on a549 nonsmall cell lung cancer cells. Int J Mol Sci 2018;19:1-18.

87. Zhimin Fu, Cao X, Liu L, et al. Genistein inhibits lung cancer cell stem-like characteristics by modulating MnSOD and FoxM1 expression. Oncol Lett 2020;20:2506-15.

88. Xia R, Xu G, Huang Y, et al. Hesperidin suppresses the migration and invasion of non-small cell lung cancer cells by inhibiting the SDF-1/CXCR-4 pathway. Life Sci 2018;201:111-20.

89. Jiang M, Zhou LY, Xu N, et al. Hydroxysafflor yellow A inhibited lipopolysaccharide-induced non-small cell lung cancer cell proliferation, migration, and invasion by suppressing the PI3K/AKT/mTOR and ERK/MAPK signaling pathways. Thorac Cancer 2019;10:1319-33.

90. Zhao Y, Yang G, Ren D, et al. Luteolin suppresses growth and migration of human lung cancer cells. Mol Biol Rep 2011;38:1115-9.

91. Kang HR, Moon JY, Ediriweera MK, et al. Dietary flavonoid myricetin inhibits invasion and migration of radioresistant lung cancer cells (A549-IR) by suppressing MMP-2 and MMP-9 expressions through inhibition of the FAK-ERK signaling pathway. Food Sci Nutr 2020;8:2059-67.

92. Wei L, Yao Y, Zhao K, et al. Oroxylin A inhibits invasion and migration through suppressing ERK/GSK-3 $\beta$ signaling in snail-expressing non-small-cell lung cancer cells. Mol Carcinog 2016;55:2121-34.

93. Su G, Chen H, Sun X. Baicalein suppresses non small cell lung cancer cell proliferation, invasion and Notch signaling pathway. Cancer Biomarkers 2018;22:13-8.

94. Zhao Z, Liu B, Sun J, et al. Scutellaria flavonoids effectively inhibit the malignant phenotypes of non-small cell lung cancer in an id1-dependent manner. Int J Biol Sci 2019;15:1500-13.

95. Wang S, Xu X, Hu Y, et al. Sotetsuflavone induces autophagy in non-small cell lung cancer through blocking $\mathrm{PI} 3 \mathrm{~K} / \mathrm{Akt} / \mathrm{m}$ TOR signaling pathway in vivo and in vitro. Front Pharmacol 2019;10:1460.

96. Unahabhokha T, Chanvorachote P, Sritularak B, et al. Gigantol Inhibits Epithelial to Mesenchymal Process in Human Lung Cancer Cells. Evidence-based Complement Altern Med 2016;2016.

97. Kowitdamrong A, Chanvorachote P, Sritularak B, et al. Moscatilin inhibits lung cancer cell motility and invasion via suppression of endogenous reactive oxygen species. Biomed Res Int 2013;2013:765894.

98. Xue X, Sun DF, Sun CC, et al. Inhibitory effect of riccardin D on growth of human non-small cell lung cancer: In vitro and in vivo studies. Lung Cancer
2012;76:300-8.

99. Zhang Y, Lian J, Wang X. Actein inhibits cell proliferation and migration and promotes cell apoptosis in human nonsmall cell lung cancer cells. Oncol Lett 2018;15:3155-60.

100.Attoub S, Arafat K, Gélaude A, et al. Frondoside A Suppressive Effects on Lung Cancer Survival, Tumor Growth, Angiogenesis, Invasion, and Metastasis. PLoS One 2013;8:e53087.

101.Liu Y, Xia X-C, Meng L-Y, et al. Alisol B 23-acetate inhibits the viability and induces apoptosis of non-small cell lung cancer cells via PI3K/AKT/mTOR signal pathway. Mol Med Rep 2019;20:1187-95.

102.Zehra B, Ahmed A, Sarwar R, et al. Apoptotic and antimetastatic activities of betulin isolated from Quercus incana against non-small cell lung cancer cells. Cancer Manag Res 2019;11:1667-83.

103.Zhang LL, Jiang XM, Huang MY, et al. Nagilactone E suppresses TGF- $\beta 1$-induced epithelial-mesenchymal transition, migration and invasion in non-small cell lung cancer cells. Phytomedicine 2019;52:32-9.

104. Yang K, Chen Y, Zhou J, et al. Ursolic acid promotes apoptosis and mediates transcriptional suppression of CT45A2 gene expression in non-small-cell lung carcinoma harbouring EGFR T790M mutations. Br J Pharmacol 2019;176:4609-24.

105.Li DD, Qin XC, Yang Y, et al. Daurinoline suppressed the migration and invasion of chemo-resistant human non-small cell lung cancer cells by reversing EMT and Notch-1 and sensitized the cells to Taxol. Environ Toxicol Pharmacol 2019;66:109-15.

106.Lai H, Wang Y, Duan F, et al. Krukovine Suppresses KRAS-Mutated Lung Cancer Cell Growth and Proliferation by Inhibiting the RAF-ERK Pathway and Inactivating AKT Pathway. Front Pharmacol 2018;9:958.

107.Zhou GZ, Shi YY, Cui LS, et al. Oxymatrine induces A549 human non-small lung cancer cell apoptosis via extrinsic and intrinsic pathways. Mol Med Rep 2018;17:1071-6.

108. Zhao L, Liu S, Che X, et al. Bufalin inhibits TGF$\beta$-induced epithelial-to-mesenchymal transition and migration in human lung cancer A549 cells by downregulating TGF- $\beta$ receptors. Int J Mol Med 2015;36:645-52.

109. Huang AC, Yang MD, Hsiao YT, et al. Bufalin inhibits gefitinib resistant NCI-H460 human lung cancer cell migration and invasion in vitro. J Ethnopharmacol 2016;194:1043-50.

110.Schneider NFZ, Geller FC, Persich L, et al. Inhibition of cell proliferation, invasion and migration by the 
cardenolides digitoxigenin monodigitoxoside and convallatoxin in human lung cancer cell line. Nat Prod Res 2016;30:1327-31.

111. Chen M, Cheng HU, Yuanyuan GUO, et al. Ophiopogonin B suppresses the metastasis and angiogenesis of A549 cells in vitro and in vivo by inhibiting the EphA2/Akt signaling pathway. Oncol Rep 2018;40:1339-47.

112. Luo C, Wang X, An C, et al. Molecular inhibition mechanisms of cell migration and invasion by coix polysaccharides in A549 NSCLC cells via targeting S100A4. Mol Med Rep 2017;15:309-16.

113. Wei C, Yao X, Jiang Z, et al. Cordycepin Inhibits Drugresistance Non-small Cell Lung Cancer Progression by Activating AMPK Signaling Pathway. Pharmacol Res 2019;144:79-89.

114. Chen SC, Chien YC, Pan CH, et al. Inhibitory effect of dihydroaustrasulfone alcohol on the migration of human non-small cell lung carcinoma A549 cells and the antitumor effect on a Lewis lung carcinoma-bearing tumor model in C57BL/6J mice. Mar Drugs 2014;12:196-213.

115.Li H, Wang Q, Wang Y, et al. Esculetin inhibits the proliferation of human lung cancer cells by targeting epithelial-to-mesenchymal transition of the cells. Cell Mol Biol 2019;65:95-8.

116. Yang X, Zhang Y, Huang Y, et al. Evodiamine suppresses Notch3 signaling in lung tumorigenesis via direct binding to $\gamma$-secretases. Phytomedicine 2020;68:153176.

117.Wang W, Gou X, Xue H, et al. Ganoderan (Gdn) regulates the growth, motility and apoptosis of non-small cell lung cancer cells through erk signaling pathway in vitro and in vivo. Onco Targets Ther 2019;12:8821-32.

118. Lu S, Ye L, Yin S, et al. Glycyrol exerts potent therapeutic effect on lung cancer via directly inactivating T-LAK cell-originated protein kinase. Pharmacol Res 2019;147:104366.

119. Chiu CC, Liu PL, Huang KJ, et al. Goniothalamin inhibits growth of human lung cancer cells through DNA damage, apoptosis, and reduced migration ability. J Agric Food Chem 2011;59:4288-93.

120.Zheng Z, Lin K, Hu Y, et al. Sulforaphane metabolites inhibit migration and invasion via microtubule-mediated Claudins dysfunction or inhibition of autolysosome formation in human non-small cell lung cancer cells. Cell Death Dis 2019;10:259.

121. Wang H, Wang L, Cao L, et al. Inhibition of autophagy potentiates the anti-metastasis effect of phenethyl isothiocyanate through JAK2/STAT3 pathway in lung cancer cells. Mol Carcinog 2018;57:522-35.
122. Chen Y, Chen JQ, Ge MM, et al. Sulforaphane inhibits epithelial-mesenchymal transition by activating extracellular signal-regulated kinase 5 in lung cancer cells. J Nutr Biochem 2019;72:108219.

123. Lee CJ, Lee MH, Yoo SM, et al. Magnolin inhibits cell migration and invasion by targeting the ERKs/RSK2 signaling pathway. BMC Cancer 2015;15:576.

124. Halim H, Chunhacha P, Suwanborirux K, et al. Anticancer and antimetastatic activities of renieramyein $M$, a marine tetrahydroisoquinoline alkaloid, in human non-small cell lung cancer cells. Anticancer Res 2011;31:193-201.

125. Ren M, Xu W, Xu T. Salidroside represses proliferation, migration and invasion of human lung cancer cells through AKT and MEK/ERK signal pathway. Artif Cells Nanomed Biotechnol 2019;47:1014-21.

126.Jiang R, Hu C, Li Q, et al. Sodium new houttuyfonate suppresses metastasis in NSCLC cells through the Linc00668/miR-147a/slug axis. J Exp Clin Cancer Res 2019;38:155.

127.Preet A, Ganju RK, Groopman JE. $\Delta 9$ -

Tetrahydrocannabinol inhibits epithelial growth factorinduced lung cancer cell migration in vitro as well as its growth and metastasis in vivo. Oncogene 2008;27:339-46.

128. Duval K, Grover H, Han LH, et al. Modeling physiological events in $2 \mathrm{D}$ vs. $3 \mathrm{D}$ cell culture. Physiology 2017;32:266-77.

129.Hamilton G, Rath B. Role of circulating tumor cell spheroids in drug resistance. Cancer Drug Resist 2019;2:762-72.

130.Amintas S, Bedel A, Moreau-Gaudry F, et al. Circulating tumor cell clusters: United we stand divided we fall. Int J Mol Sci 2020;21:2653.

131. Um E, Oh JM, Granick S, et al. Cell migration in microengineered tumor environments. Lab Chip 2017;17:4171-85.

132.Xu X, Jiang Z, Wang J, et al. Microfluidic applications on circulating tumor cell isolation and biomimicking of cancer metastasis. Electrophoresis 2020;41:933-51.

133. Khanna C, Hunter K. Modeling metastasis in vivo. Carcinogenesis 2005;26:513-23.

Cite this article as: Albuquerque $\mathrm{C}$, Manguinhas $\mathrm{R}$, Costa JG, Gil N, Codony-Servat J, Castro M, Miranda JP, Fernandes AS, Rosell R, Oliveira NG. A narrative review of the migration and invasion features of non-small cell lung cancer cells upon xenobiotic exposure: insights from in vitro studies. Transl Lung Cancer Res 2021;10(6):2698-2714. doi: 10.21037/tlcr-21-121 
Table S1 Main in vitro assays used to assess migration and invasion in NSCLC cells

\begin{tabular}{|c|c|c|c|}
\hline Assay & Endpoint & Information & Ref. \\
\hline \multicolumn{4}{|l|}{ Migration } \\
\hline $\begin{array}{l}\text { Transwell migration assay } \\
\text { (Boyden chamber) }\end{array}$ & Number of migrated cells & Single-cell migration, chemotaxis & $(9-12,24-32,34-40,46,55,56,64,69,71,72,74,79,83,88,89,96,97,99,103,108,109,111,114,122,123,125,127)$ \\
\hline Wound-healing (scratch) assay & Migration area/width & Collective migration, EMT & $(4,24,25,27-32,34,39,45,46,48,50,51,53,54,56-62,65,67,68,70-73,75,76,77,79-81,83-92,94-102,104-114,116-124,126,127)$ \\
\hline Fence assay & Migration area & Collective migration, EMT & (18) \\
\hline Time-lapse cell tracking & Cell migration path & Collective or single-cell migration & $(19,20,63)$ \\
\hline Cell exclusion zone assay & Migration area & Collective migration, EMT & $(19,21,22,66)$ \\
\hline Spheroid migration assay & Migration area & Migration from cell cluster & (23) \\
\hline \multicolumn{4}{|l|}{ Invasion } \\
\hline $\begin{array}{l}\text { Transwell invasion assay } \\
\text { (Boyden chamber) }\end{array}$ & Number of invasive cells & Single-cell invasion through ECM & $(4,11,12,25-29,31,32,34-40,45,46,48,50-55,57,59,60,62-64,67,68,71,73-77,79,80-89,92-103,105,109,110-113,115,117,120-127)$ \\
\hline Spheroid invasion assay & Invasion area & $\begin{array}{l}\text { Single or collective invasion from } \\
\text { cluster }\end{array}$ & $(21,47)$ \\
\hline 3D cell tracking & Invasion distance & Single-cell invasion & $(47)$ \\
\hline Gelatin zymography & Zymograms & MMPs activity & $(26,28,40,45,46,62,77,79,91,98,102,114,119,123)$ \\
\hline
\end{tabular}

3D, three-dimensional; EMT, epithelial to mesenchymal transition; ECM, extracellular matrix; MMPs, matrix metalloproteinases 
Table S2 Overview of in vitro studies on migration and invasion of NSCLC cells exposed to lung carcinogens and other toxic contaminants

\begin{tabular}{|c|c|c|c|c|c|}
\hline Group & Carcinogen/Contaminant & NSCLC cell line & Methodology (concentrations used*) & Key findings** & Ref. \\
\hline \multirow[t]{19}{*}{ Tobacco smoke } & \multirow[t]{3}{*}{$B(a) P$} & A549 & Transwell migration and invasion assays (10 $\mathrm{nM}$ and 1,000 nM) & B(a)P significantly increased cell migration and invasion through up-regulating IL-8, CCL2, and CCL3 expression & (55) \\
\hline & & \multirow[t]{2}{*}{ A549, YTMLC } & Wound-healing assay & \multirow[t]{2}{*}{$\mathrm{B}(\mathrm{a}) \mathrm{P}$ increased the number of metastatic cells and TNF- $\alpha$ had a role in this development } & \multirow[t]{2}{*}{ (56) } \\
\hline & & & Transwell migration assay $(1,2,5,10$ and $20 \mu \mathrm{M})$ & & \\
\hline & \multirow[t]{6}{*}{ Cadmium } & \multirow[t]{6}{*}{ A549 } & Wound-healing assay $(10 \mu \mathrm{M}$ and $20 \mu \mathrm{M})$ & Notch1, along with HIF-1 $\alpha$ and IGF-1R/Akt/ERK/SGK1 signalling pathways, promote malignant progression stimulated by Cd & (58) \\
\hline & & & Transwell migration and invasion assays ( $2 \mu \mathrm{M})$ & Upregulation of HMGA2 plays an important role in Cd-enhanced migration and invasion & (37) \\
\hline & & & Transwell migration and invasion assays (not stated) & Cd induced an increase in cell migration and invasion by promoting autophagy & (38) \\
\hline & & & Wound-healing assay & \multirow[t]{2}{*}{ TGIF might play a crucial role in invasion and migration of cells exposed to $\mathrm{Cd}$} & \multirow[t]{2}{*}{ (57) } \\
\hline & & & Transwell invasion assay $(0.5 \mu \mathrm{M}$ and $1 \mu \mathrm{M})$ & & \\
\hline & & & Transwell migration and invasion assays $(0.5 \mu \mathrm{M}$ and $2 \mu \mathrm{M})$ & Exposure to $\mathrm{Cd}$ increased the expression of $\mathrm{p}$-ERK, enhancing migration and invasion & (35) \\
\hline & \multirow[t]{5}{*}{ Nicotine } & A549, H1299 & Transwell invasion assay $(100 \mathrm{\mu g} / \mathrm{mL})$ & Nicotine promoted cell migration through upregulation of LINC00460 & (52) \\
\hline & & \multirow[t]{2}{*}{ A549 } & Wound-healing assay & \multirow[t]{2}{*}{ Nicotine induced proliferation, invasion, and migration of tumor cells through the mediation of $a 7-\mathrm{nAChRs}$} & \multirow[t]{2}{*}{ (50) } \\
\hline & & & Transwell invasion assay $(0.01,0.1$ and $1 \mu \mathrm{M})$ & & \\
\hline & & \multirow[t]{2}{*}{ A549, H1650 } & Wound-healing assay & \multirow[t]{2}{*}{ ID1, after induction by nicotine, promoted migration and invasion by increasing the expression of STMN3 and GSPT1 genes } & \multirow[t]{2}{*}{ (51) } \\
\hline & & & Transwell invasion assay $(1 \mu \mathrm{M})$ & & \\
\hline & \multirow[t]{5}{*}{ NNK } & \multirow[t]{3}{*}{ H1299 } & Wound-healing assay & \multirow[t]{3}{*}{ NNK activated the $\mathrm{c}-\mathrm{SrC} / \mathrm{PKC} / \mathrm{FAK}$ loop, which promoted metastasis } & \multirow[t]{3}{*}{ (53) } \\
\hline & & & Cell migration assay kit & & \\
\hline & & & Transwell invasion assay (100 pM) & & \\
\hline & & \multirow[t]{2}{*}{ A549, H157 } & Wound-healing assay & \multirow[t]{2}{*}{ Twist protein and mRNA expression were increased by NNK, and it was necessary for NNK promotion of migration and invasion } & \multirow[t]{2}{*}{ (54) } \\
\hline & & & Transwell invasion assay ( 2 and $5 \mu \mathrm{M})$ & & \\
\hline \multirow[t]{14}{*}{ Air pollution } & \multirow[t]{4}{*}{ BPA } & \multirow[t]{4}{*}{ A549 } & Wound-healing assay & \multirow[t]{2}{*}{ BPA can promote the in vitro migration and invasion via upregulation of MMPs and GPER/EGFR/ERK1/2 signals } & (34) \\
\hline & & & Transwell migration and invasion assays $(10 \mu \mathrm{M})$ & & \\
\hline & & & Transwell invasion assay & Snail-1/Cx43/ERRy was identified as a novel signalling pathway through which BPA promoted metastasis & (63) \\
\hline & & & Time-lapse cell tracking $(10,50,100,300 \mathrm{nM}$ and $10 \mu \mathrm{M})$ & & \\
\hline & gNO & A549 & Wound-healing assay & gNO promoted metastasis through a mechanism involving the iNOS-dependent MMP-2 activity & (62) \\
\hline & & & Transwell invasion assay & & \\
\hline & & & Gelatin zymography $(1.0,2.5$, and $5.0 \mu \mathrm{M})$ & & \\
\hline & Oxy-PAHs & A549 & Wound-healing assay & Exposure to Oxy-PAHs (9-fluorenone) induced invasion and migration of cells by the activation of EMT & (24) \\
\hline & & & Transwell migration assay $(0.16,0.8,4,20$ and $100 \mu \mathrm{M})$ & & \\
\hline & PM2.5 & A549 & Wound-healing assay & PM2.5 exposure induced ROS, which activates loc 146880 expression. The IncRNA, in turn, up-regulates autophagy and promotes & (59) \\
\hline & & & Transwell invasion assay $\left(16 \mu \mathrm{g} / \mathrm{cm}^{2}\right)$ & & \\
\hline & & A549, H1299 & Wound-healing assay $\left(50 \mu \mathrm{g} / \mathrm{cm}^{2}\right)$ & PM2.5 exposure induced proliferation and motility & (61) \\
\hline & & $\mathrm{H} 1299, \mathrm{H} 520$ & Wound-healing assay & Cell migration, invasion, EMT and autophagy were enhanced when cells were treated with cigarette smoke extract and PM2.5 alone or & (60) \\
\hline & & & Transwell invasion assay $\left(25 \mu \mathrm{g} / \mathrm{cm}^{2}\right)$ & in combination & \\
\hline Other & AFB1 & A549 & Wound-healing assay $(2.5 \mu \mathrm{M})$ & AFB1 promoted cell migration through upregulation of IRS2 via induction of Src phosphorylation & (65) \\
\hline & Arecoline & A549, H520, H460 & Cell exclusion zone assay $(40 \mu \mathrm{M})$ & Arecoline stimulated cell migration by activating the EGFR/c-Src/FAK signalling pathway via mAChR3 & (66) \\
\hline & Isoflurane & A549, H1299 & Wound-healing assay & Isofflurane activated the Akt-mTOR signalling pathway resulting in the promotion of cells' proliferation, migration, and invasion & (67) \\
\hline & & & Transwell invasion assay ( 1 and 2\%) & & \\
\hline & Riboflavin & A549, H3255, Calu-6 & Transwell migration and invasion assays (50, 100, 200 and $400 \mu \mathrm{M})$ & Riboflavin at higher doses increased cell growth as well as invasion and migration & (64) \\
\hline
\end{tabular}




\begin{tabular}{|c|c|c|c|c|c|}
\hline Group & Naturat bibactive & Nsclicatline & nodology (concentrations sseded" & Key findings" & Ret. \\
\hline \multirow[t]{11}{*}{ 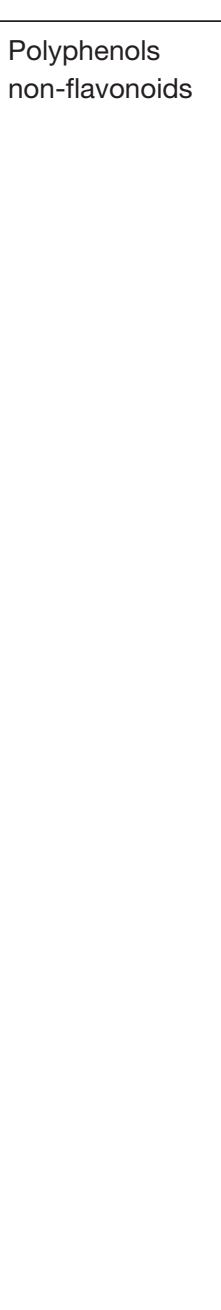 } & Curcumin & 8010 & 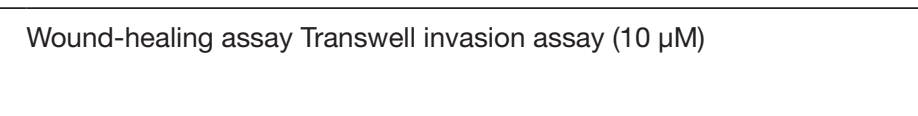 & 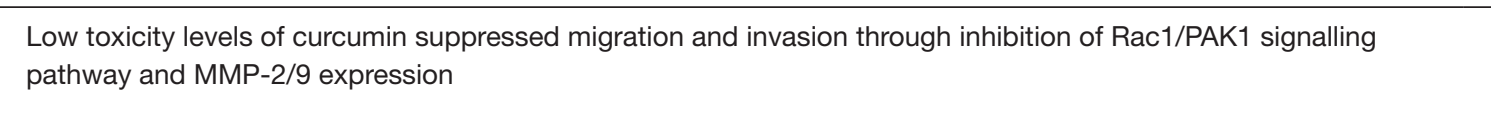 & (68) \\
\hline & & A599 & Transwell migration assay/(5and 10 um) & Curcumins Supposessed porliteration and migratic & (60) \\
\hline & Fiphemerant & H460 & 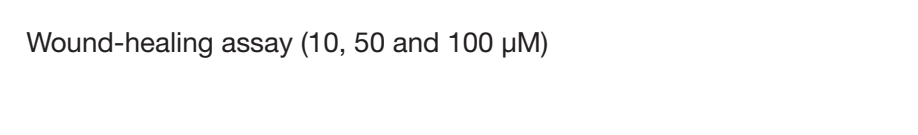 & 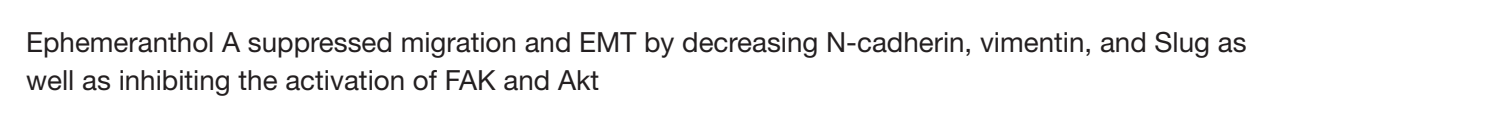 & (70) \\
\hline & Honokial & A599, H460, H226, H1299 & 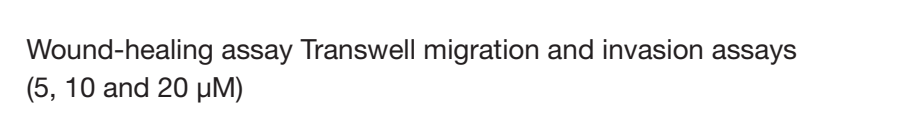 & 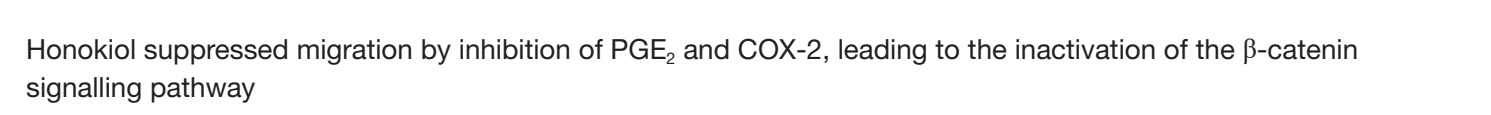 & (71) \\
\hline & & As59, H460 & 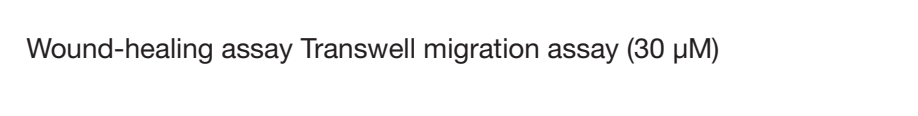 & 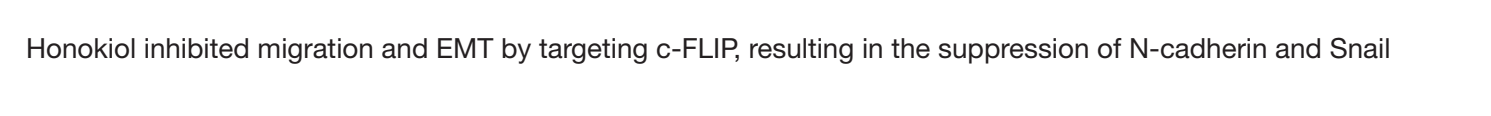 & (12) \\
\hline & & A549 & 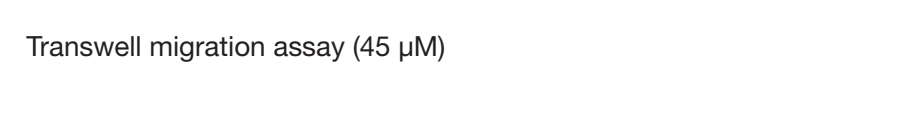 & 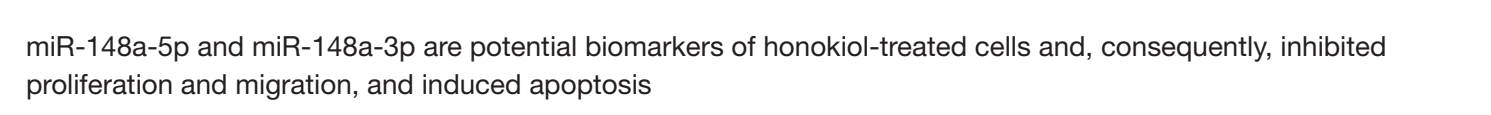 & (9) \\
\hline & Mangatien & As99, H460, H520 & 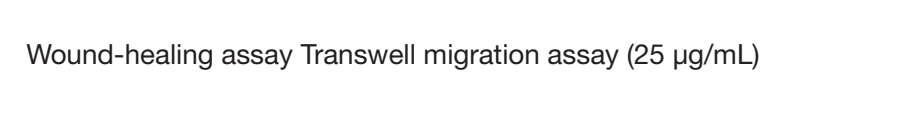 & 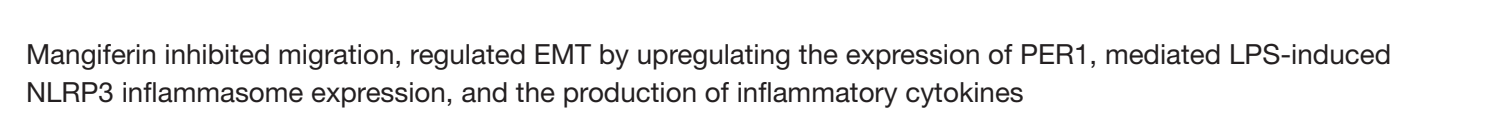 & 180 \\
\hline & Provormanain & Ha60, H282,A549 & 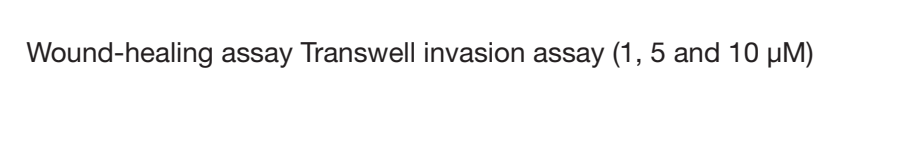 & 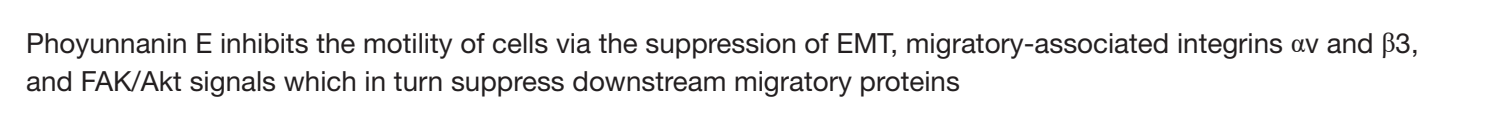 & (33) \\
\hline & Resveratrol & A549 & 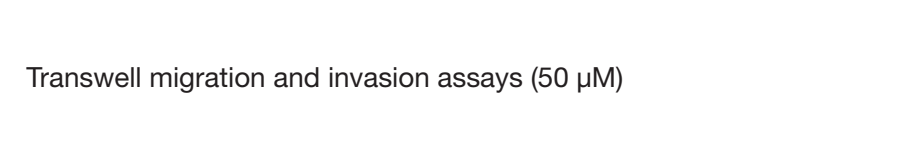 & 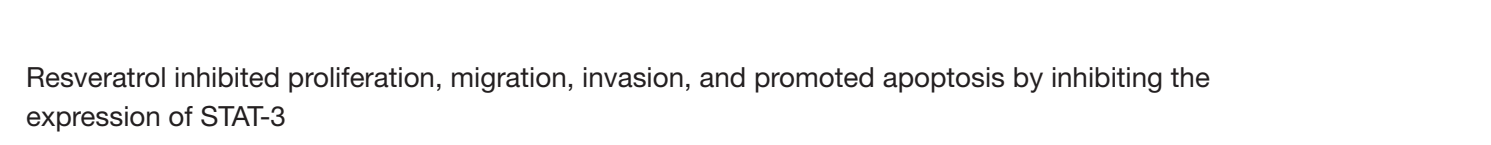 & (44) \\
\hline & & & Wund-healing assay Transwel invasion assay 255 MM) & 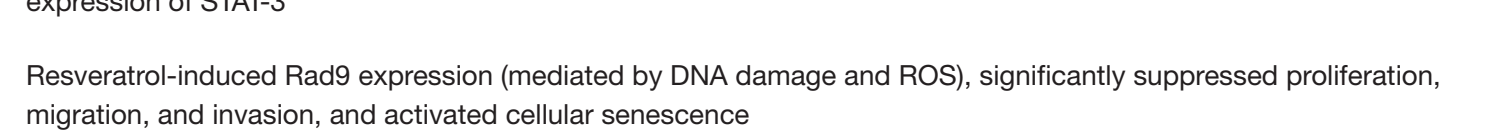 & (5) \\
\hline & Rotetein & A549 & 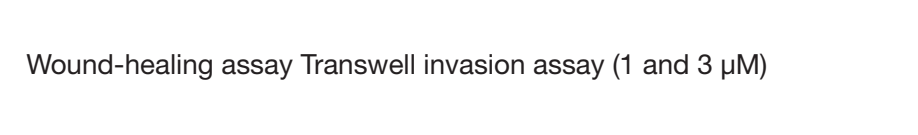 & 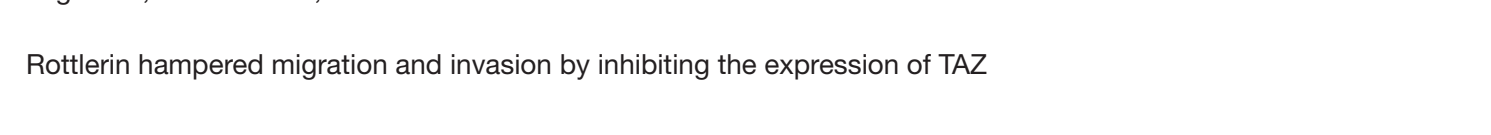 & (76) \\
\hline \multirow[t]{30}{*}{ avonodis } & Acecetin & As49 & 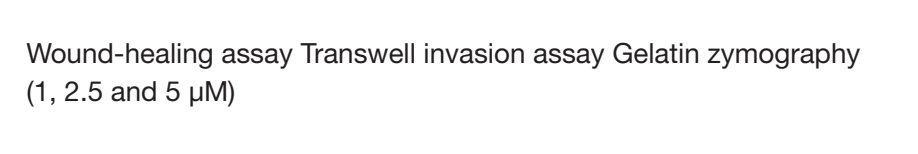 & 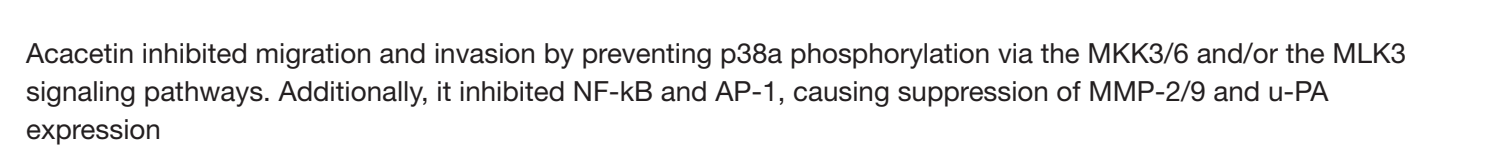 & (77) \\
\hline & Atalartataluonen & Ass9, 550 & 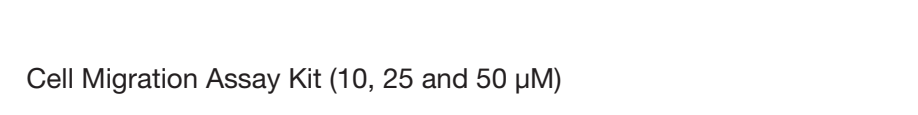 & 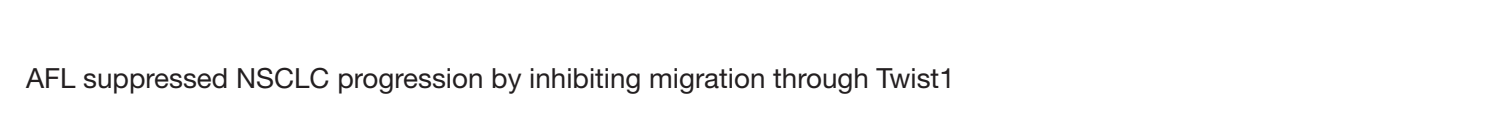 & (8) \\
\hline & Antrocyanins & A549 & 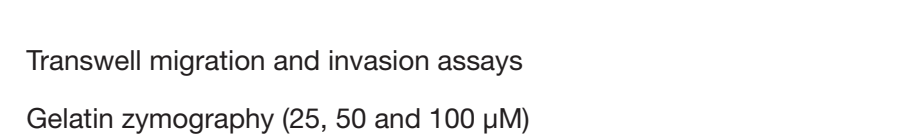 & 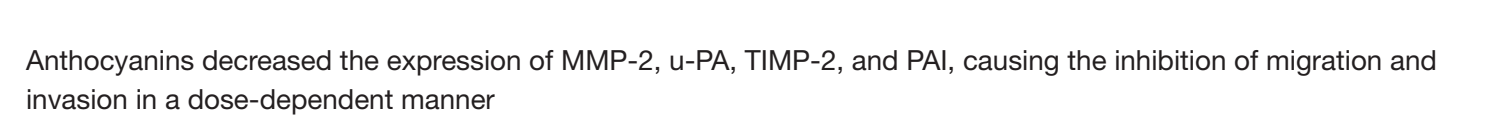 & 400 \\
\hline & & H12299 & Wound-neaing assay & 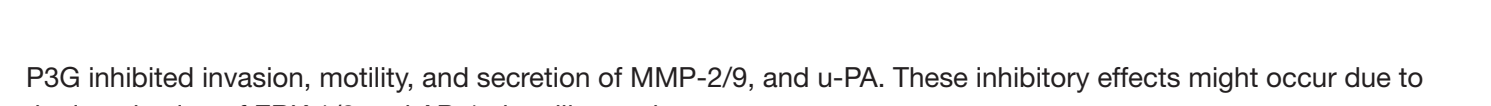 & (79) \\
\hline & & & 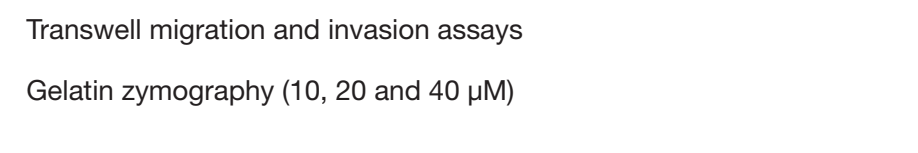 & 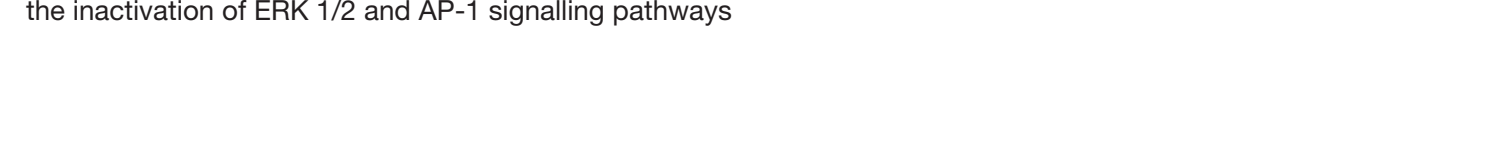 & \\
\hline & & & 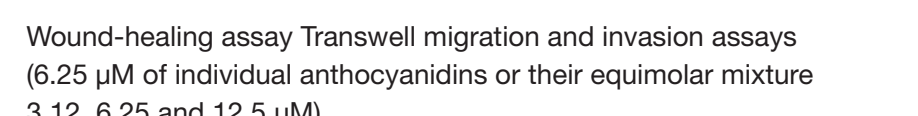 & 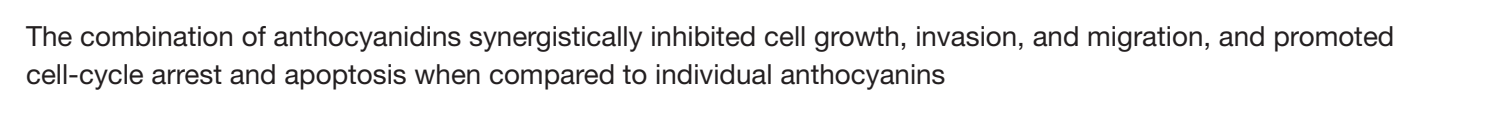 & |cter \\
\hline & Atoonin E & As99, H660, & 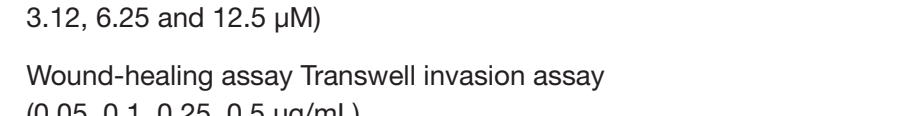 & 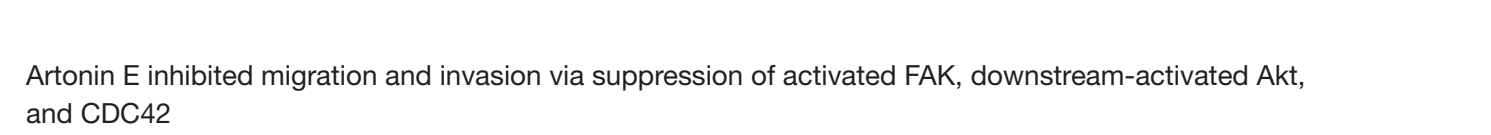 & ${ }^{(80)}$ \\
\hline & BOA.A & Assa & 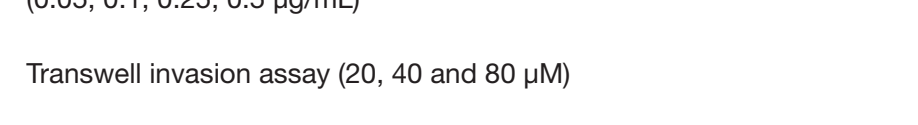 & 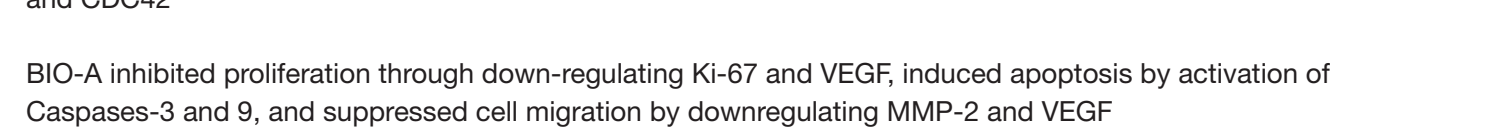 & (82) \\
\hline & 管 & ${ }^{4460}$ & 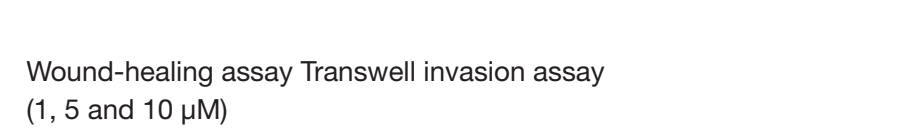 & 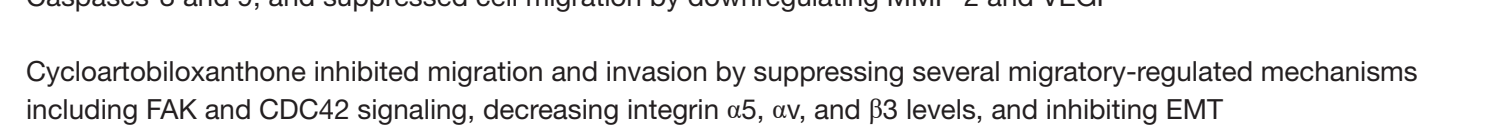 & (81) \\
\hline & Deguelin & He22 & 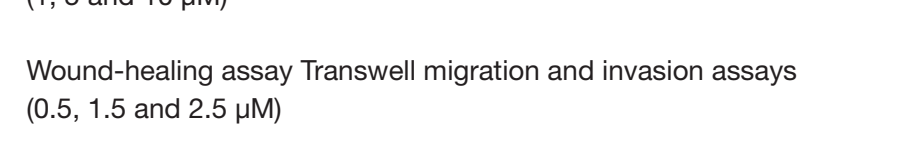 & 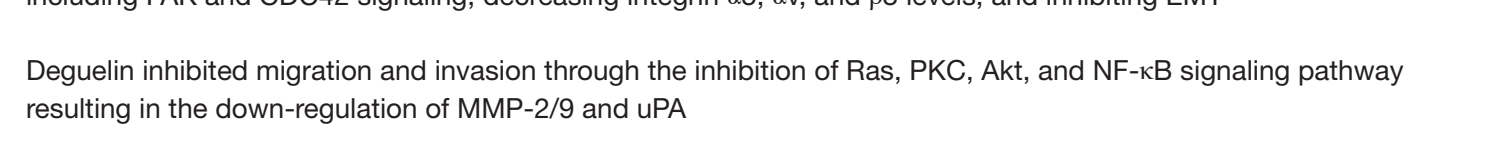 & (8) \\
\hline & & 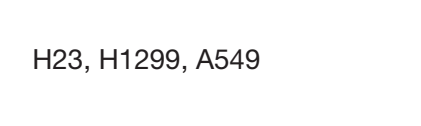 & 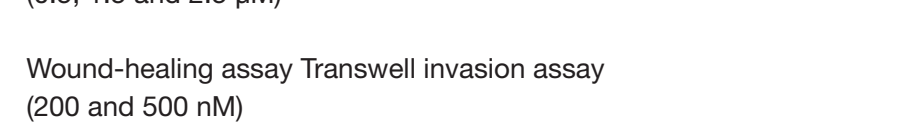 & 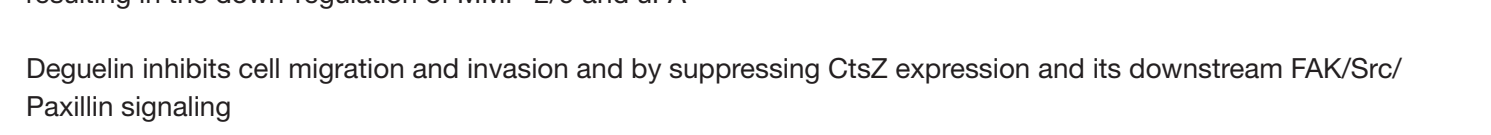 & (84) \\
\hline & $\mathrm{ECG}$ & Asta & 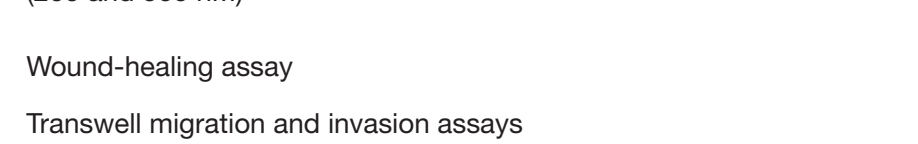 & 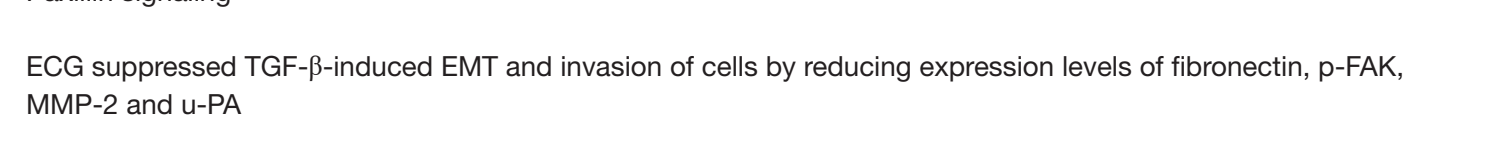 & (4) \\
\hline & & & 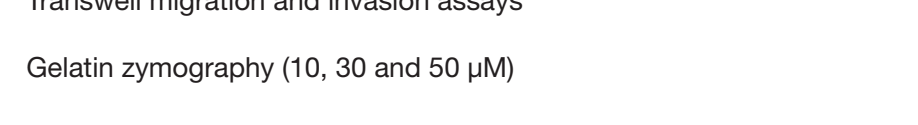 & & \\
\hline & Eoca & A549 & 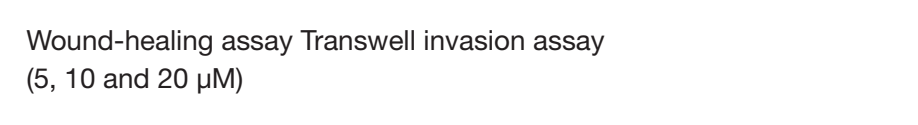 & 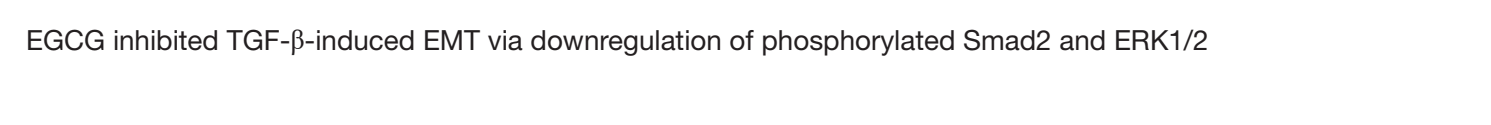 & (i) \\
\hline & Fisatin & A549 & $\begin{array}{l}\text { Wound-healing assay } \\
\text { Transwell migation and inv }\end{array}$ & 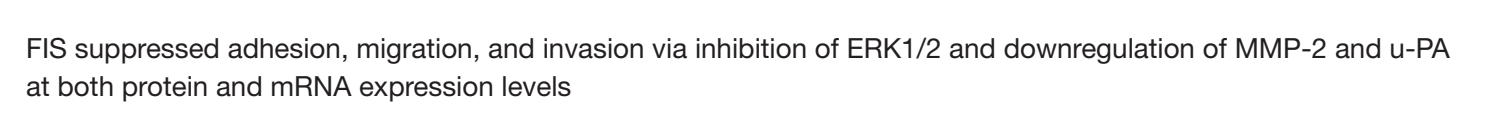 & (28) \\
\hline & & & Gelatin zymogranhy $(1,5$ and 10 MM) & & \\
\hline & & & 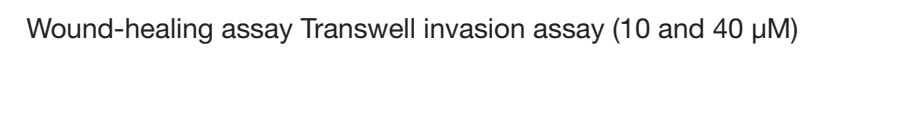 & 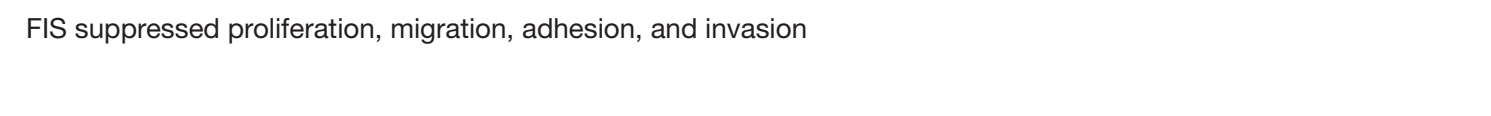 & (48) \\
\hline & & & Wound healing assay Transwell inasiona & 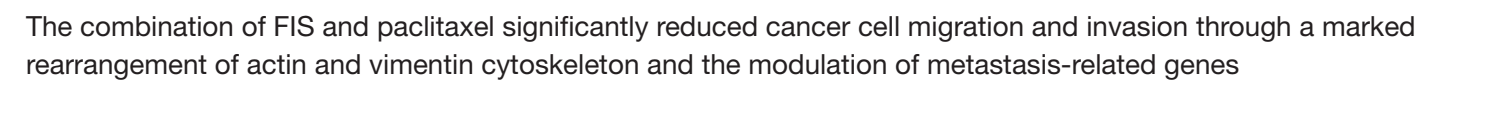 & (6) \\
\hline & & A596, 12298 & 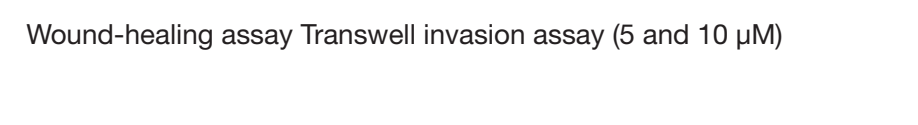 & 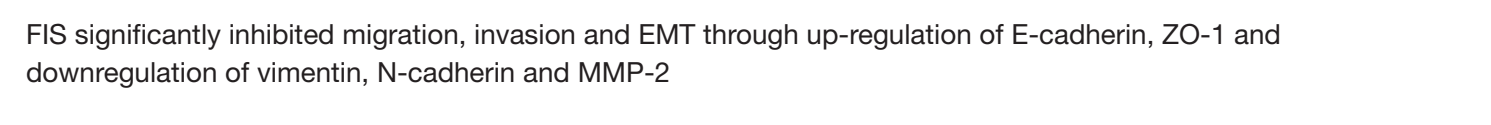 & (4) \\
\hline & Gensisen & A599, H460 & 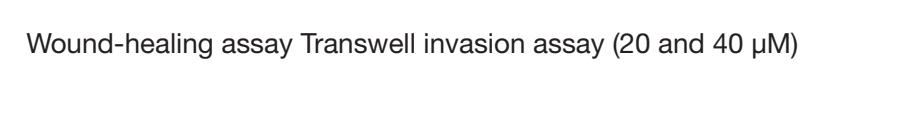 & Genisten inibitited migration and ivasion & ${ }^{807}$ \\
\hline & Heseperidn & A 499, , H660, H1975 & 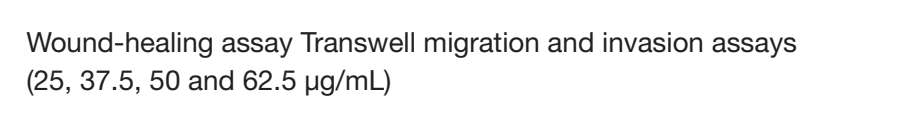 & Hesperidin inibited the migratory and inv & (om \\
\hline & Hydidoxsathor yent & A559, 12299 & 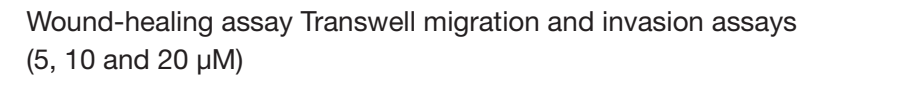 & 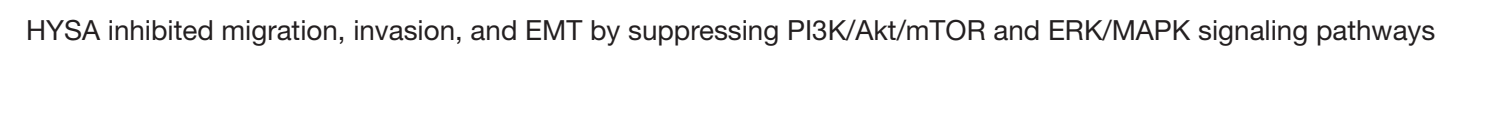 & (89) \\
\hline & Lutoolin & A549 & Wound-healing assay $(50$ MM) & 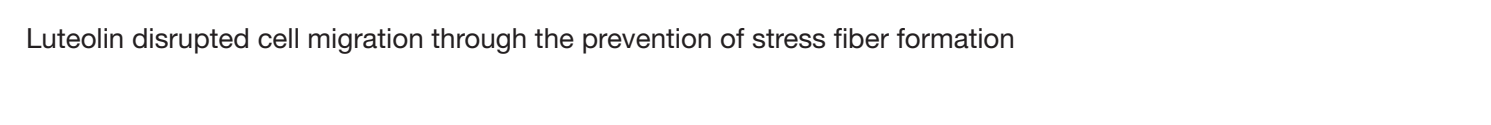 & ${ }^{800}$ \\
\hline & Morin & Asa9 & 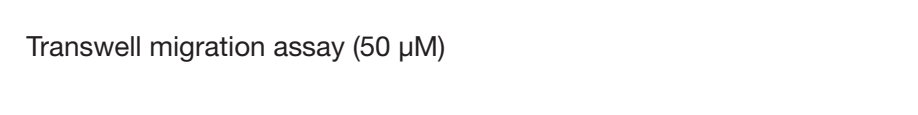 & 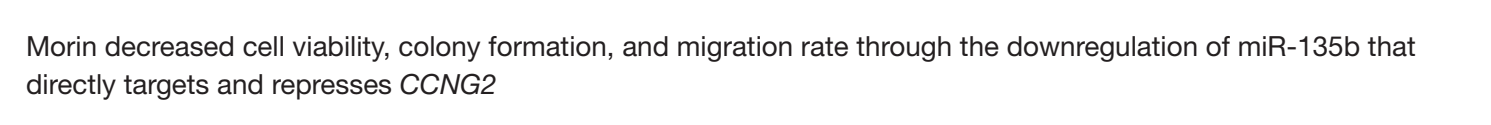 & (10) \\
\hline & Myricetin & As49 & 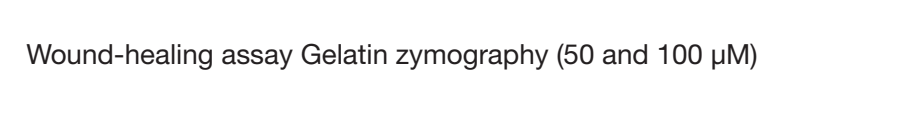 & 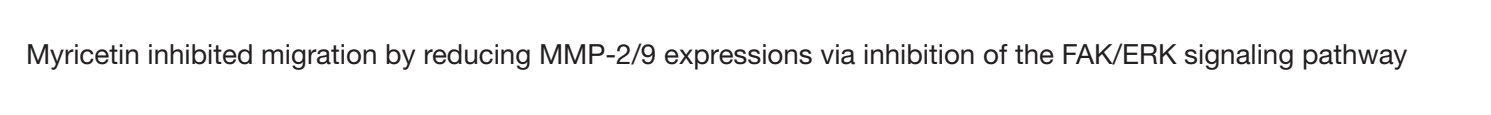 & (91) \\
\hline & Ouecosatn & Ast9, & 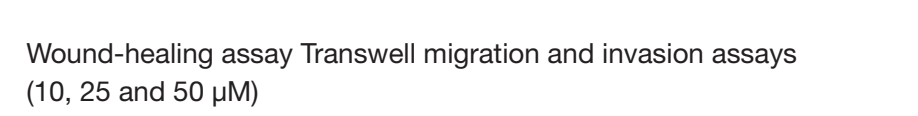 & 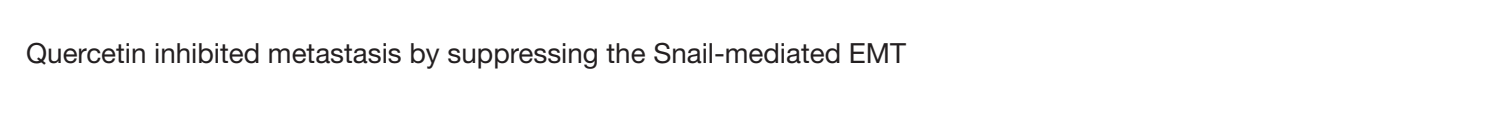 & (3i) \\
\hline & scublebras & A599, H12099 & 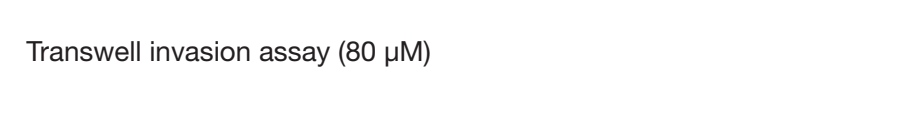 & 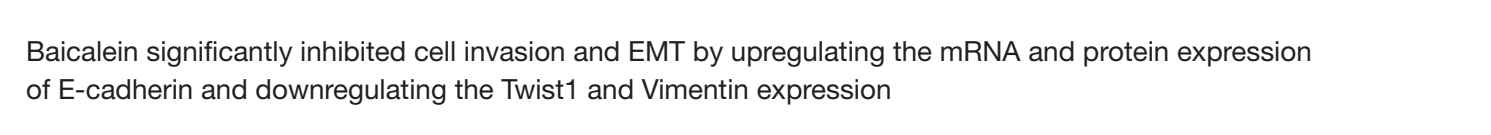 & (8) \\
\hline & & & 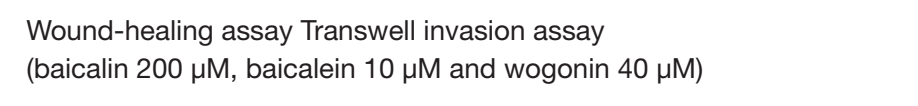 & 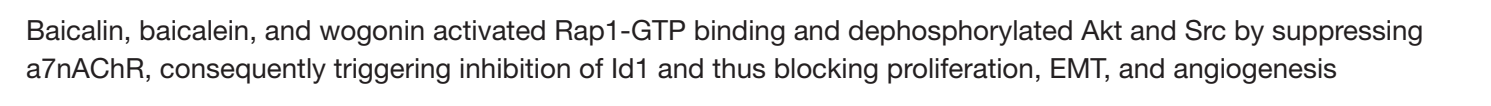 & (94) \\
\hline & & As99, s50 & 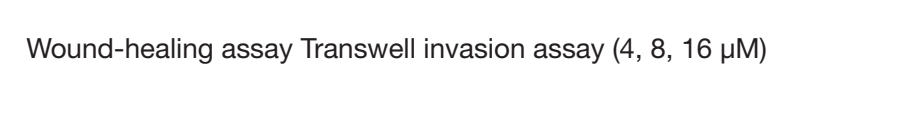 & 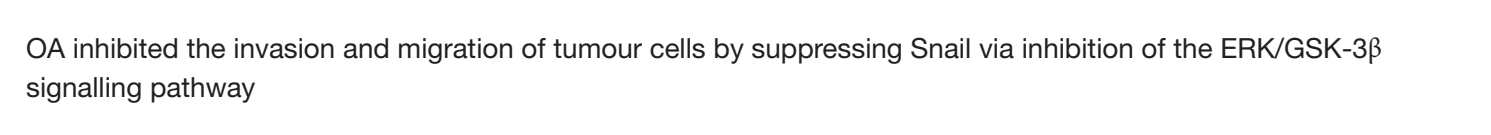 & (92) \\
\hline & solesturatarone & H1650 & 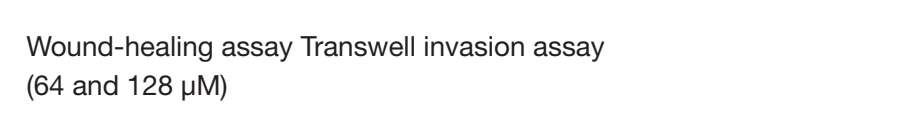 & 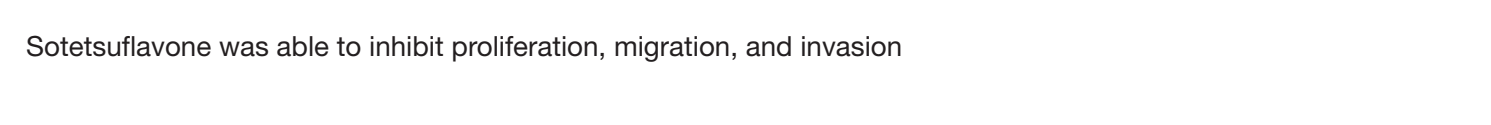 & (9) \\
\hline \multirow[t]{6}{*}{ Bbonzls } & cimsonoboberaxy & Hato, He22 & 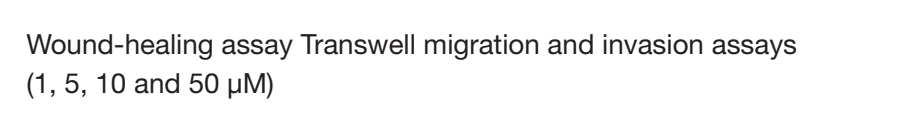 & 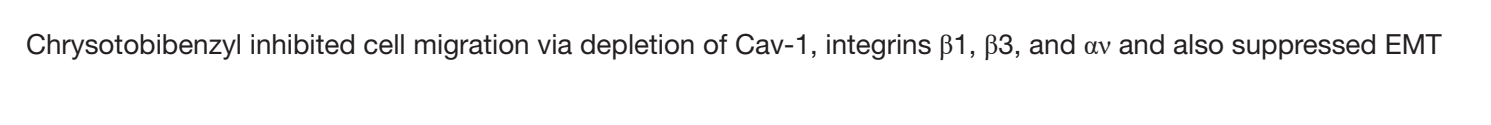 & (2) \\
\hline & Gigantal & H460, $\mathrm{H292}$ & 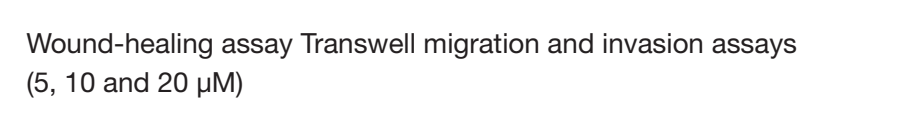 & 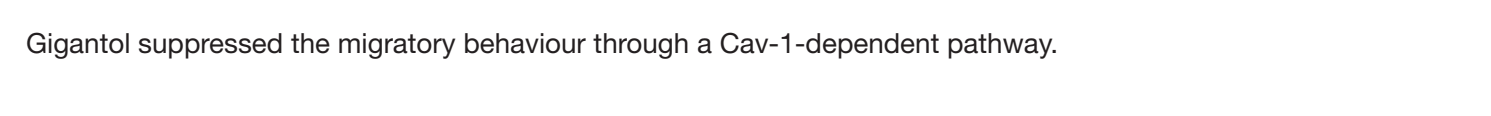 & (29) \\
\hline & & H460 & 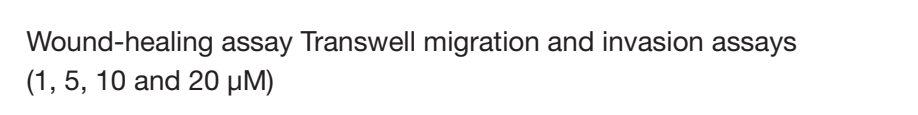 & 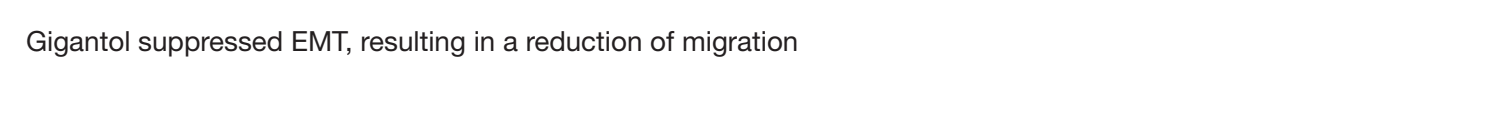 & (96) \\
\hline & Mosesatin & ${ }^{423}$ & 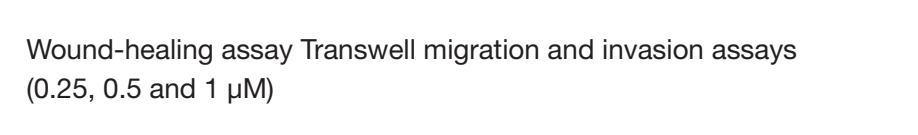 & scatilin mibited celln & ${ }^{8 \pi}$ \\
\hline & Aicacarin D & A549 & 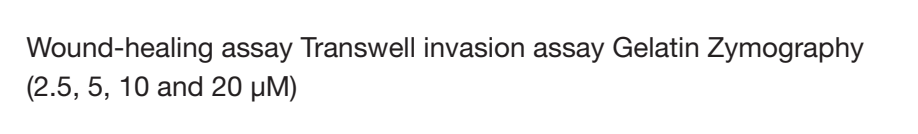 & 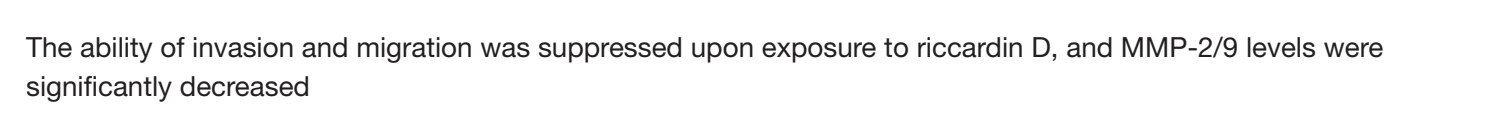 & (⿻) \\
\hline & TOB & H292 & 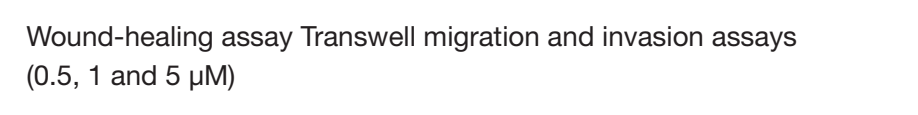 & 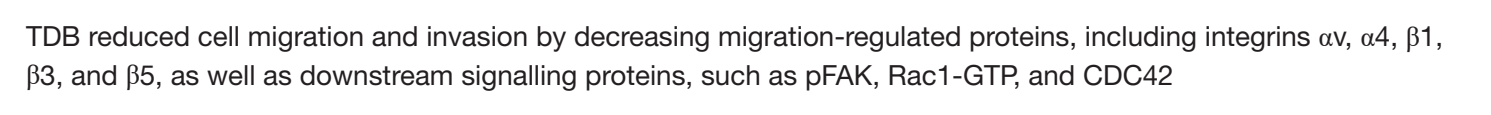 & (39) \\
\hline \multirow[t]{7}{*}{ Tepeness } & Adtein & AS99,950 & 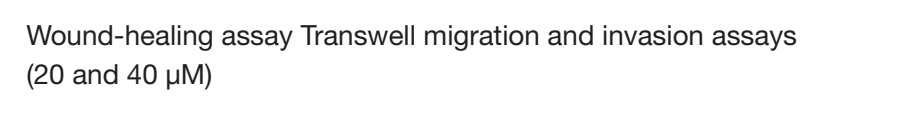 & Actein suppossesed cell migation and tivasion & (99) \\
\hline & AlioliB & A549 & nammin & way & (101) \\
\hline & Boulin & H460 & 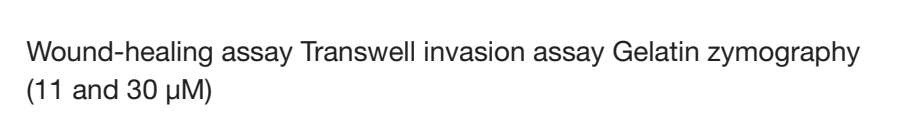 & 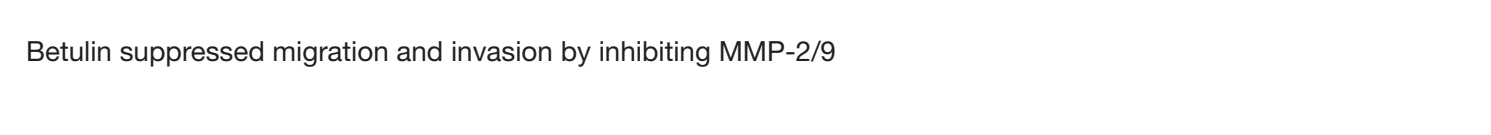 & (102) \\
\hline & Fondoside A & LMMas & 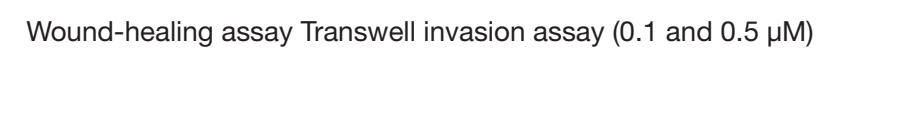 & 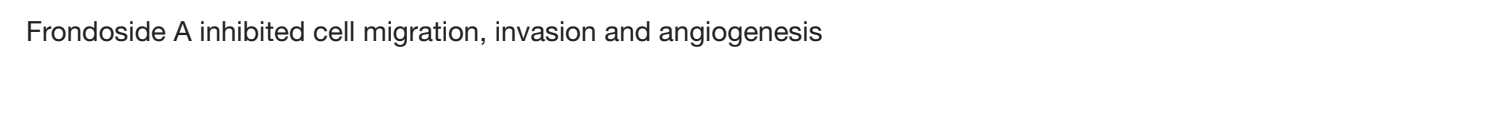 & 1000 \\
\hline & Nagabatore E & As99 & 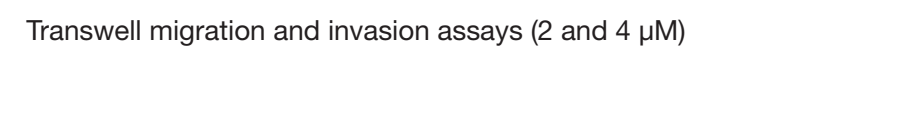 & 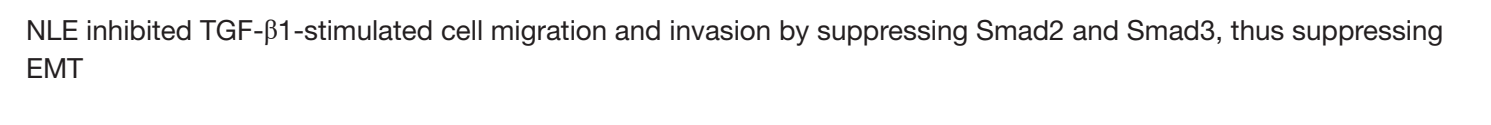 & $\log ^{100}$ \\
\hline & Tripolide & A599, , H460, H558 & vell migration and ivasion assays (10 nM) & 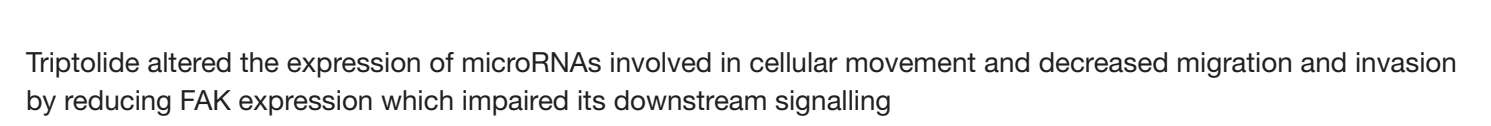 & (36) \\
\hline & Urosolicacid & H1975 & 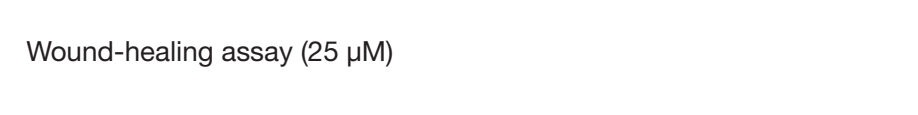 & 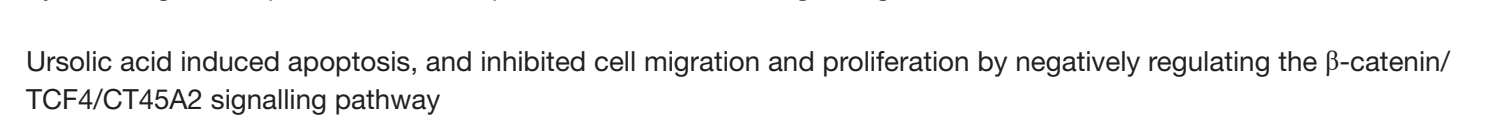 & (1004) \\
\hline atabolds & Darimoline & As49 & 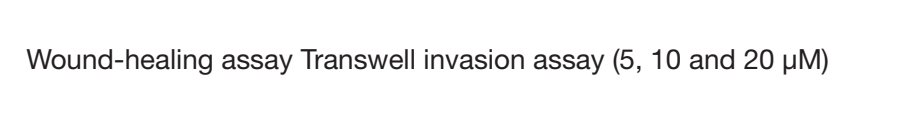 & 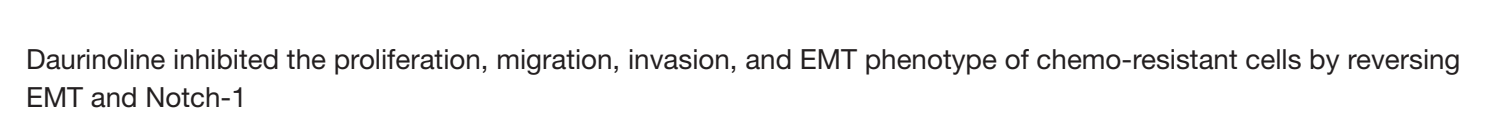 & (105) \\
\hline & Kuntomine & As99, 4,460 & 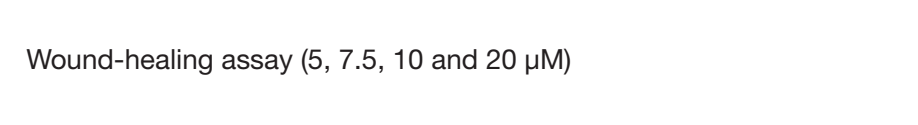 & 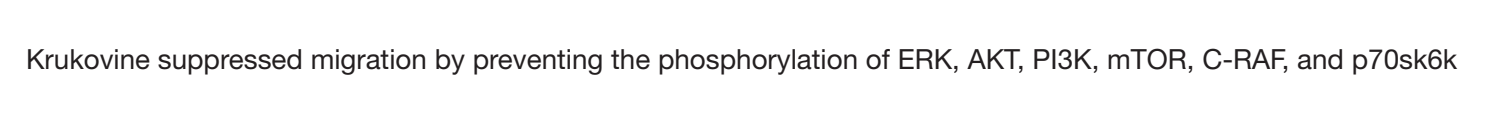 & (1006) \\
\hline & oxymatrine & assa & 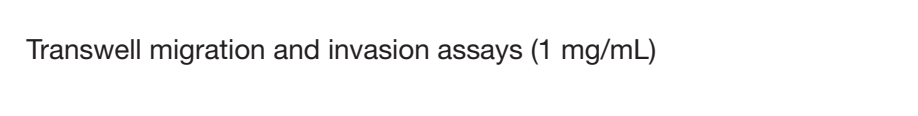 & uT inhbited cancer rogogession ar & (11) \\
\hline & & & thealing assay $(1.5$ and 2 mg/mL) & 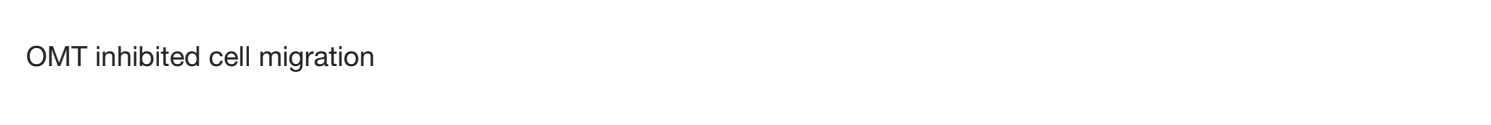 & (107) \\
\hline Sterods & Buatin & Haso & 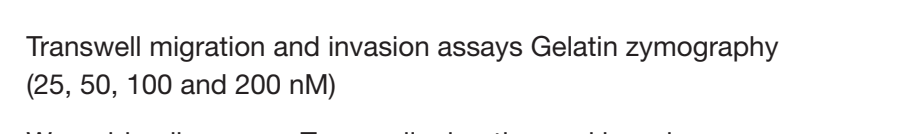 & 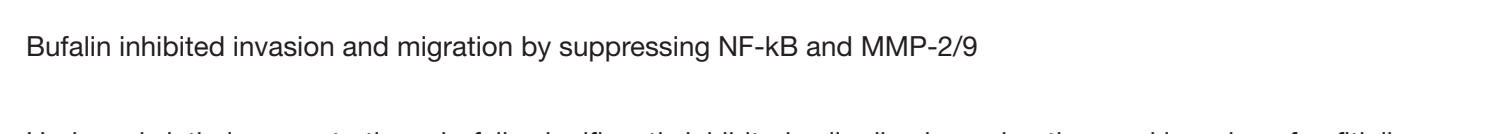 & (20) \\
\hline & & & 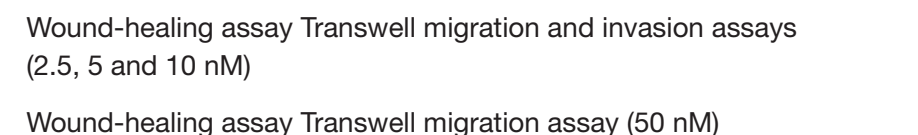 & 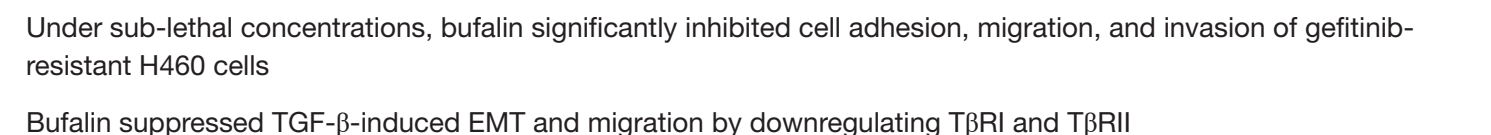 & (1098) \\
\hline & cardenofides & A549 & 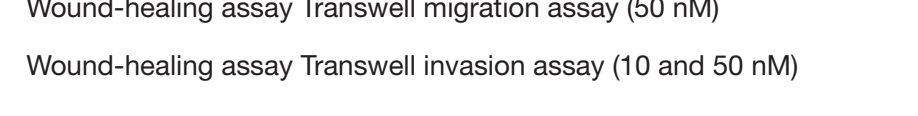 & 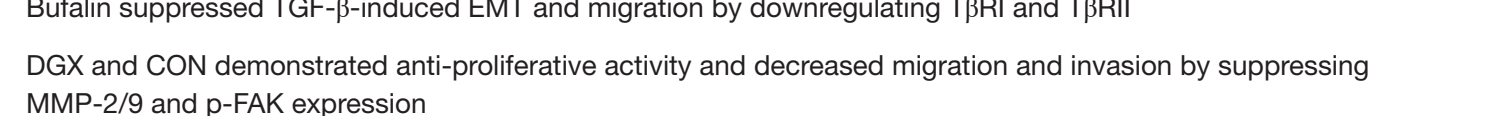 & (100) \\
\hline & oppioposonin $B$ & A599 & 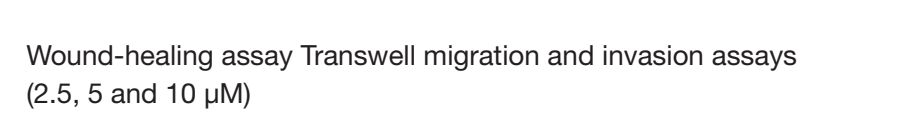 & dons sgananing & (111) \\
\hline onters & Coxposolsacac & As49 & 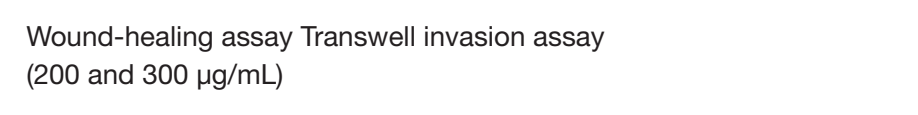 & colx polysace & (112) \\
\hline & cortsyeapin & ${ }^{\mathrm{PCO}, \mathrm{H} 1 \mathrm{9} 75}$ & 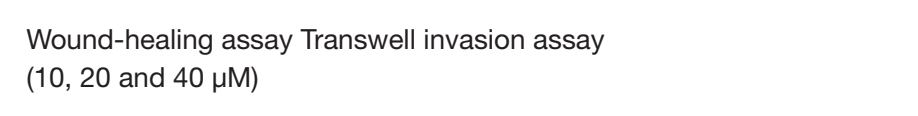 & 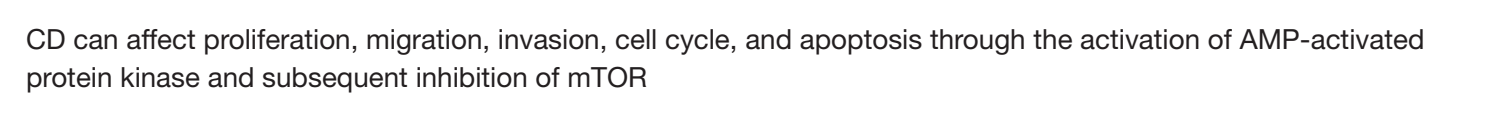 & (113) \\
\hline & & A569 & 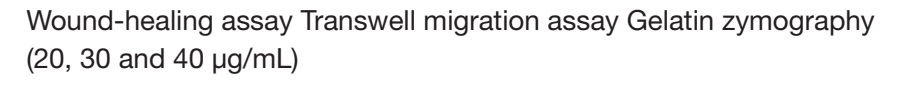 & 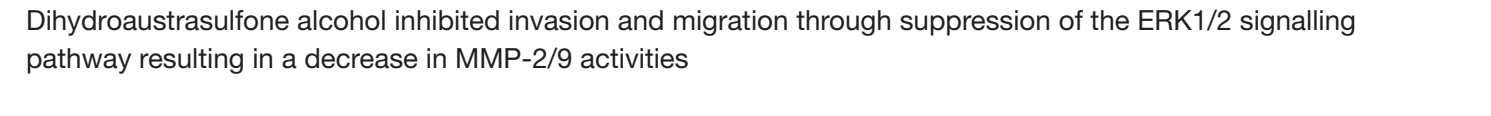 & (114) \\
\hline & Escoutain & ass9 & Iinvasion assay (5 and 20 MM) & 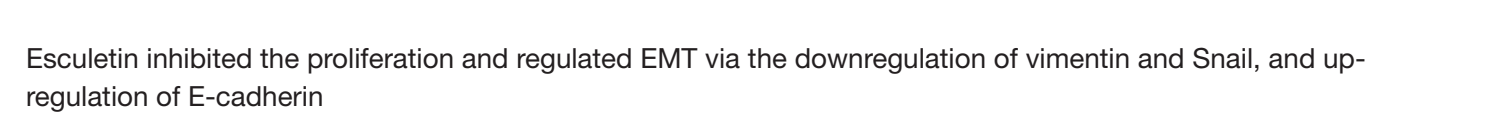 & (115) \\
\hline & Evodaramine & As49 & 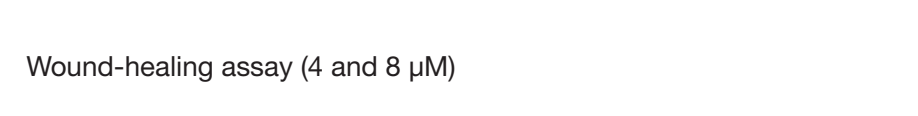 & 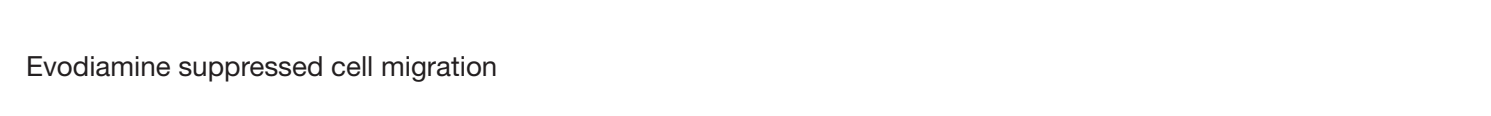 & (1160) \\
\hline & Ganostean & asi9 & 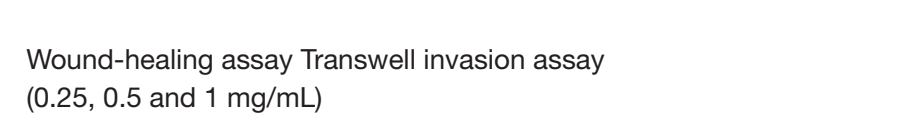 & 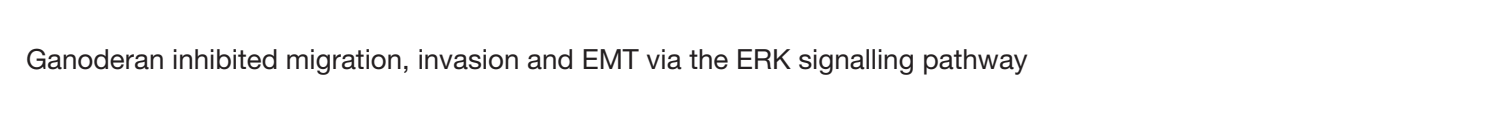 & (117) \\
\hline & axicrora & As49 & 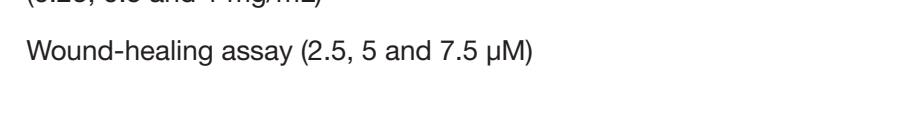 & 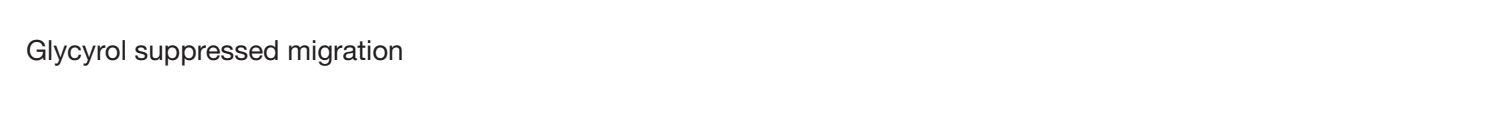 & (118) \\
\hline & conotis & o & 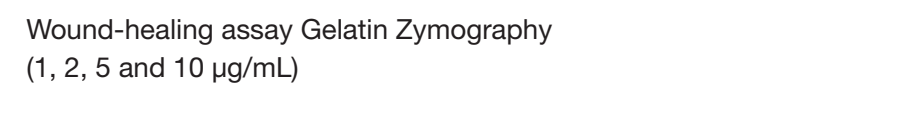 & 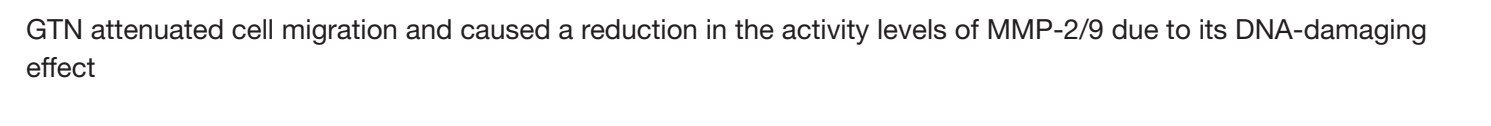 & (1199) \\
\hline & ocya & As49, SKK- & 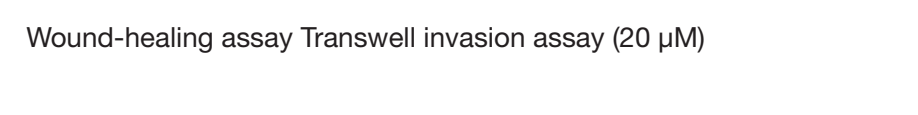 & 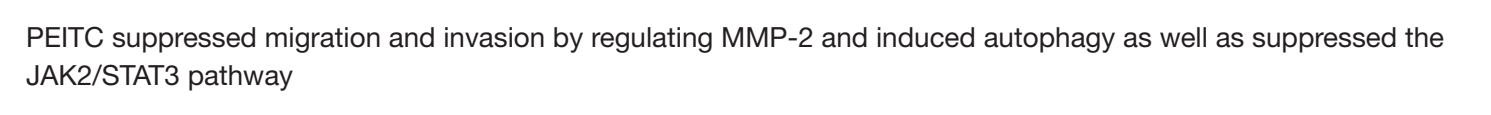 & (121) \\
\hline & & As99 & aling ssay trat & 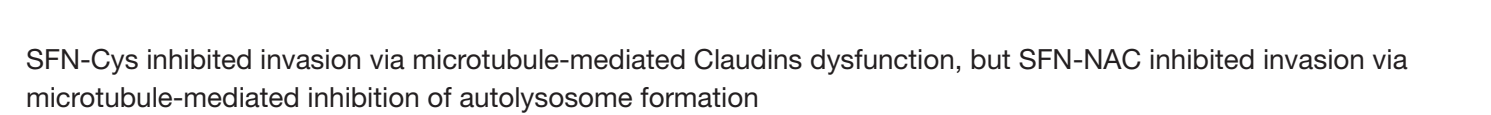 & (120) \\
\hline & & H1299,950,95C & 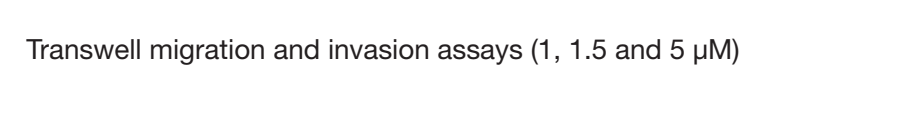 & 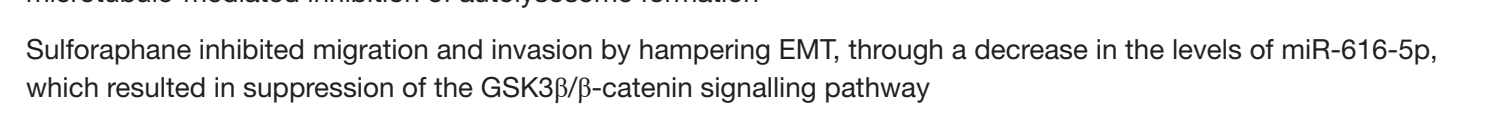 & (12) \\
\hline & & A589. & 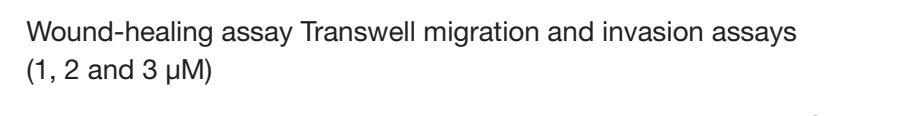 & 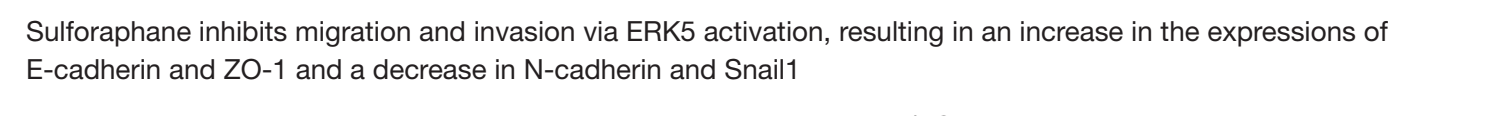 & (122) \\
\hline & Masolin & A59, 19795 & 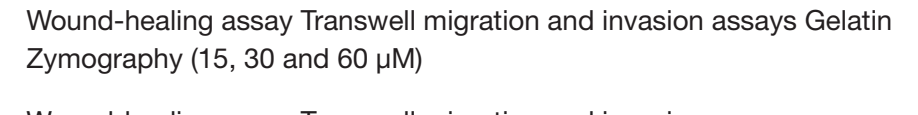 & 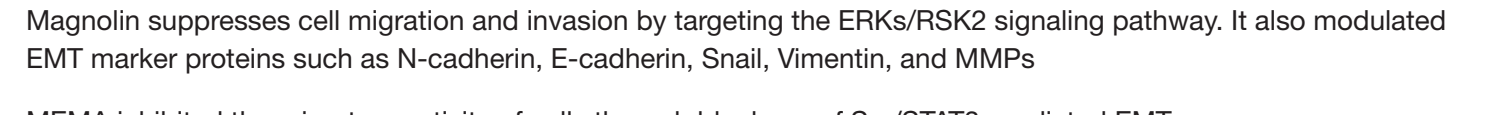 & (123) \\
\hline & 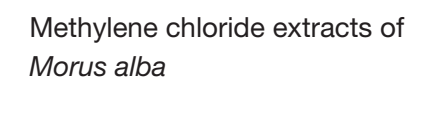 & 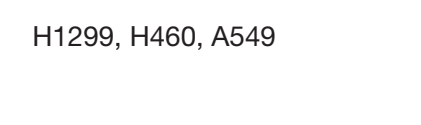 & 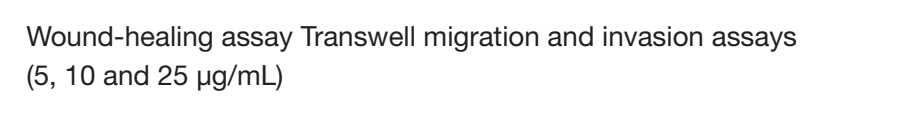 & & ${ }^{(32)}$ \\
\hline & Renitea & наяо & m & & (124) \\
\hline & 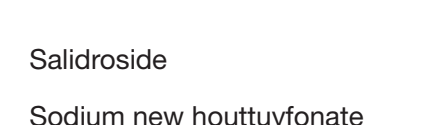 & A699 & 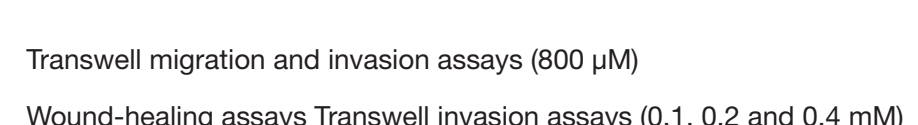 & dum & (125) \\
\hline & & A & 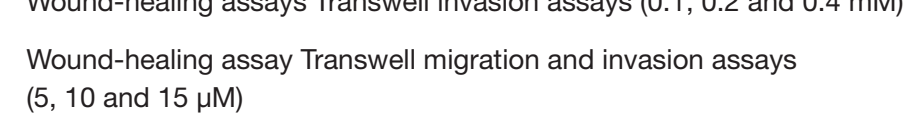 & 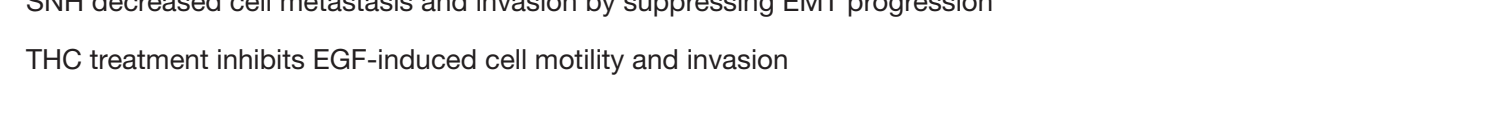 & 年 \\
\hline & & A599 & 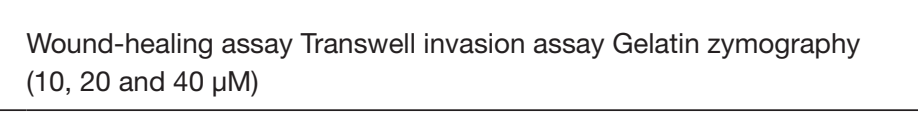 & 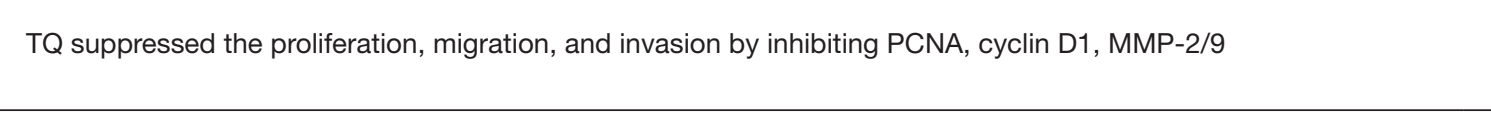 & (45) \\
\hline & & 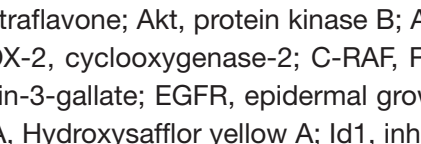 & 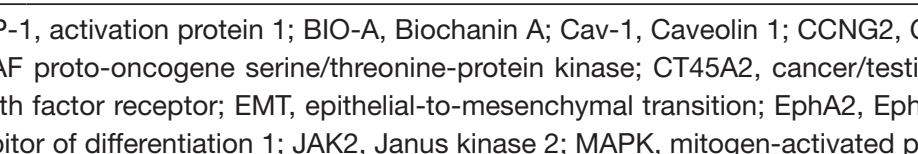 & 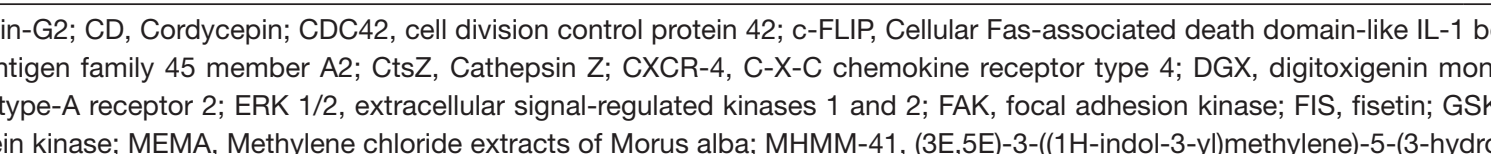 & 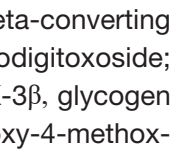 \\
\hline 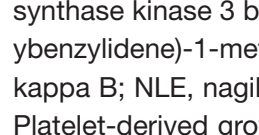 & 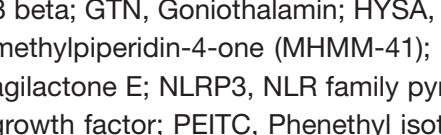 & 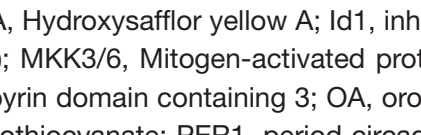 & 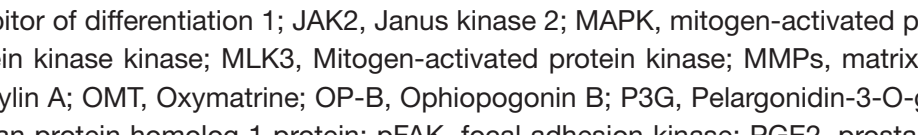 & 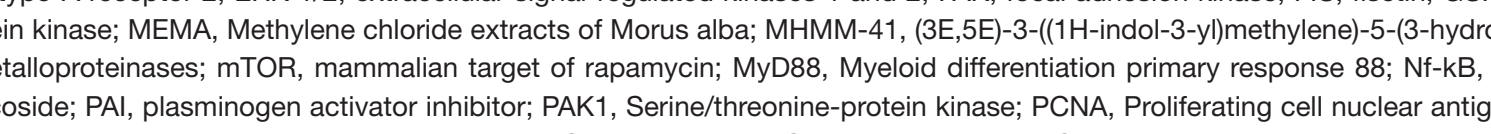 & \\
\hline & & & 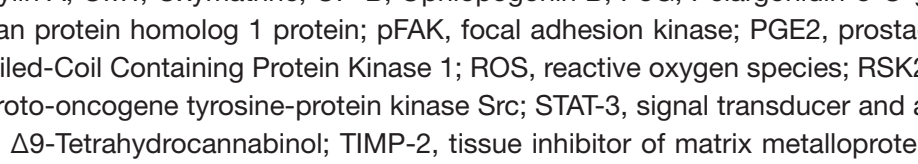 & 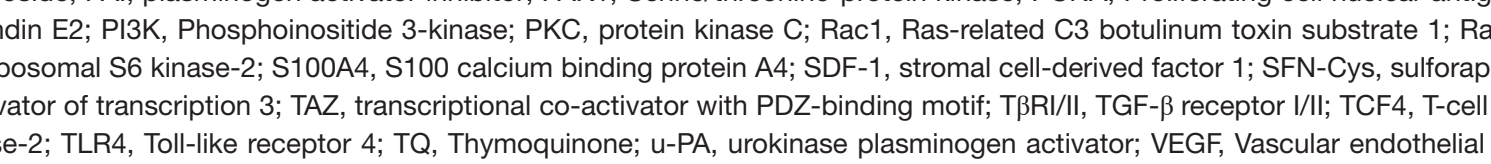 & \\
\hline
\end{tabular}

